\title{
Appendix 3 \\ Individual Descriptions of Human \\ Skeletal Remains at Man Bac: 2005 and 2007 Series
}

\author{
Hirofumi Matsumura ${ }^{1}$, Nguyen Lan Cuong² and Damien G. \\ Huffer ${ }^{3}$
}

${ }^{1}$ Department of Anatomy, Sapporo Medical University, Japan

${ }^{2}$ The Vietnamese Institute of Archaeology

${ }^{3}$ The Australian National University

In Appendix 1 sex, age-at-death and mortuary variables were described for each burial. In this chapter the preservation of each burial from the 2004/5 and 2007 seasons are summarised (with photographs provided for the best preserved sets of remains). For adult specimens the cranial morphology is also described and when sexually dimorphic characters are discussed, Acsádi and Nemeskéri's (1970) scoring system is used. Dental occlusal wear was also recorded: Smith's (1984) system for anterior teeth (incisors, canines and premolars); and Scott's (1979) system for molars. For the dentition, tooth presence and condition is recorded via standard recording protocols, as per the following example.

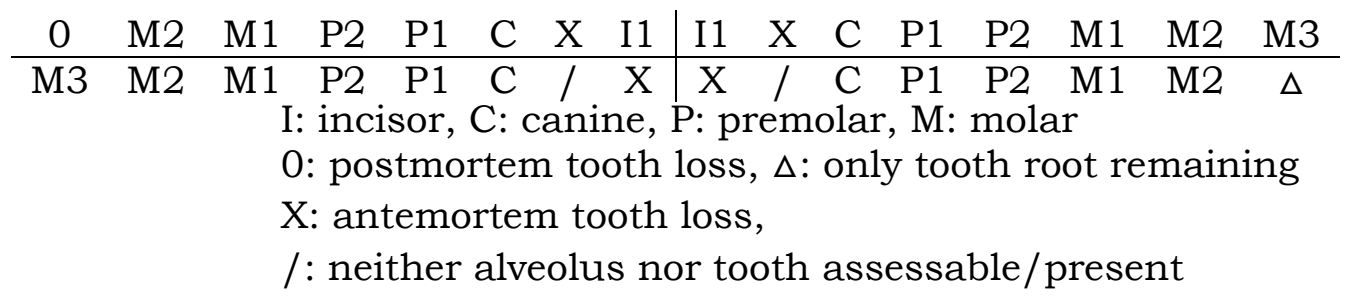

HUMAN REMAINS FROM THE 2005 SERIES

\section{MB05M 1:}

This burial consists of numerous small fragments of infracranial bones (ribs, the distal ends and epiphyses of both femora and humeri, etc.), as well as the bifurcated skull of one individual. The deciduous teeth are present and completely erupted, except for the second deciduous molars with developing roots.

\section{MB05M2:}

The nearly complete skeleton of a neonate. The skeleton is somewhat disarticulated, the cranium is very thin, and no dentition has erupted. Most of the post cranial bones are well preserved. The skull includes a section of the right 


\section{H. MATSUMURA ET AL.}

frontal, both parietals, and the mandible and maxilla. The deciduous mandibular first molars and central incisors are present within the alveolus.

\section{MB05M3:}

The cranium is in a moderate state of preservation. The mandible and a portion of maxillary alveoli are present and nearly complete. The fragile facial skeleton is highly fragmented. Almost the entire post cranial skeleton is present without severe damage. All deciduous tooth crowns were completely formed but still within the alveoli.

\section{MB05M4:}

Only several large fragments of the calvaria and a diaphyseal section of one humeral shaft remain, together with two small, worn deciduous teeth; the lower canine and first molar. The dental roots are developing, and the eruption of the deciduous molar was incomplete.

\section{MB05M5:}

Most of the post-cranial skeleton, including the cranium, is nearly complete apart from the fragmented zygomatico-facial region, the left femur and both feet. The second deciduous molars have begun to erupt.

\section{MB05M6:}

This burial consists solely of the right forearm, both os coxae, both femora, tibiae and fibulae.

\section{MB05M7:}

A partially preserved skeleton with only the cranium, right arm and leg elements, right os coxa, a few ribs and vertebrae preserved. None of the deciduous teeth have erupted, but are partially formed within their alveoli. The cranium was fragmented into small pieces.

\section{MB05M8:}

A partially preserved skeleton. The maxillary region, all dentition, the feet, the entire vertebral column, all ribs, the left arm elements, left clavicle, and the right arm elements (except for the distal humerus) are all missing.

\section{MB05M9:}

Skull: almost complete. The forehead of the frontal bone is narrow and the frontal tubercle is clear. The parietal bones are not angled at the sagittal suture, and the frontal slopes backwards steeply. The supranasal suture is absent. The glabella region, superciliary arches and nasal root are flat. The orbital shape is rather round and supraorbital foramina exist on both sides. The zygomatic bones are laterally projecting. The temporal lines are not distinct on the parietal bones. The size of the mastoid process is moderate (score: 3). The external occipital protuberance is weakly protruding, while both superior and inferior nuchal lines are distinctive, and the nuchal plane is moderately rugged. The coronal, sagittal and lambdoidal sutures are not fused ectocranially. Internal suture synostosis is unknown due to soil filling the endocranium. The cranial index is 80.5 (Martin No. 8:1), indicating 
the cranium is brachyocephalic. The upper facial index is 51.9 (Martin No. 48:45), categorising the proportion of facial height to breadth as medium. The mandibular body is relatively robust, with well reflecting angles and developed pterygoid muscle attachment surfaces. The ramus has a strong posterior inclination. The mental eminence is moderately protruding (score: 3). Dental preservation:

\begin{tabular}{cccccccc|cccccccc}
0 & M2 & M1 & P2 & P1 & C & X & I1 & I1 & $\Delta$ & C & P1 & P2 & M1 & M2 & X \\
\hline M3 & M2 & M1 & P2 & P1 & C & I2 & I1 & I1 & I2 & C & P1 & P2 & M1 & M2 & M3
\end{tabular}

There is incisor occlusal over-bite.

Postcranial skeleton: the remains are in a good state of preservation. Paired upper limb bones include nearly complete scapulae, humeri, radii and ulnae. The lower limb bones of the os coxae, femora, tibiae, fibulae and patellae of both sides are also well preserved. The deltoid muscle attachment area of the humerus is robust. The leg muscles are also well developed, determined from the pilastric form of the linea aspera of the femora, and the high degree of curvature of the femoral shafts. The vertebrae, sacrum and ribs also remain in good condition.

\section{MB05M 10:}

Very good preservation; only missing the right os coxa, distal femur, hand, wrist and radius, all removed by an intrusive pit or post-hole. The deciduous molars show heavy wear, whereas the permanent teeth are unworn (score: 0-1). Dental preservation:

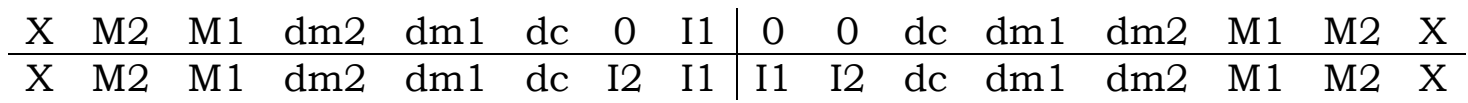

\section{MB05M11:}

Skull: complete, with only the lateral portion of the right zygomatic bone being damaged. The width of the forehead is moderate and the frontal tubercle is relatively prominent. The parietal bones are slightly angled at the sagittal suture. The frontal is perpendicularly elevated at the forehead. Both supranasal sutures are absent. The glabella region and nasal root are flat, while the superciliary arches are prominently ridged. The cranial index is 78.6 (Martin No. 8:1), indicating a mesocephalic cranium. The facial skeleton is high (upper facial height: $70 \mathrm{~mm}$ ) and relatively narrow in proportions (the upper facial index: 53.8). Orbital shape is rather round with no supraorbital foramina on either side. The zygomatic bones are prominently projecting laterally. The temporal lines are distinct on the parietal bones. The mastoid process is of moderate size (score: 3). The external occipital protuberance is moderate and the crest is not marked (score: 3), while both the superior and inferior nuchal lines are distinct. The nuchal plane is very rugged. The coronal, sagittal and lambdoidal sutures are open ectocranially, while the state of endocranial synostosis is not assessable due to soil filling the endocranium. The mandibular body is rather robust, with well developed pterygoid muscle attachment surfaces. The angle is slightly reflected and the ramus is narrow with a marked posterior inclination. The mental eminence is moderate (score: 3). Dental preservation: 


\begin{tabular}{cccccccc|cccccccc} 
M3 & M2 & M1 & P2 & 0 & C & X & 0 & 0 & X & C & P1 & P2 & M1 & M2 & 0 \\
\hline X & M2 & M1 & P2 & P1 & C & I2 & I1 & I1 & I2 & C & P1 & P2 & M1 & M2 & X
\end{tabular}

The tooth crown surfaces are flat due to attrition (anterior teeth: score 3, molars: score 4-5), except for the third molars (score: 0).

Postcranial skeleton: the post-cranial remains are in a good state of preservation, except for the lower leg and foot bones. Paired upper limb bones include the scapulae, humeri, radii and ulnae, which are all nearly complete. The humeral and femoral shafts are slender, and most muscle attachment areas are weakly developed. As for the lower limb bones, only the os coxae and femora are preserved well. The tibiae, fibulae, and feet are missing, likely removed by the later burial of MB05M18. The vertebrae, sacrum, and ribs are in good condition.

\section{MB05M 12:}

Bone preservation is relatively good, with the legs below the patellae missing, also due to the later intrusion of $2005 \mathrm{M} 18$. The skull is complete and the metopic suture has not yet fused. All the deciduous teeth are fully erupted, except for the second molars which are partially erupted.

\section{MB05M13:}

Skull: good state of preservation and gracile overall. The forehead is relatively broad. The parietal bones are not angled at the sagittal suture. The frontal is perpendicularly elevated at the forehead, and the supranasal suture is absent. The glabella region, superciliary arches and nasal root are flat, while the orbital shape is rather square. Supraorbital foramina are not present on either side. The zygomatic bones display minimal lateral projection. The temporal lines are distinct on the parietal bones. The mastoid process is of a moderate size (score: 3). The external occipital protuberance is weak (score: 2), but both the superior and inferior nuchal lines are distinct, with a smooth nuchal plane. The coronal, sagittal and lambdoidal sutures are open ectocranially, but unassessed internally due to soil filling the endocranium. The mandibular body is also gracile, and the mental eminence is weak (score 2), although the chin protrudes prominently. The gonial region is not everted and the pterygoid muscle attachment is weakly developed. The rami slope backwards steeply. Dental preservation:

\begin{tabular}{clllllll|llllllll}
$\mathrm{X}$ & $\mathrm{M} 2$ & $\mathrm{M} 1$ & $\mathrm{P} 2$ & $\mathrm{P} 1$ & $\mathrm{C}$ & $\mathrm{I} 2$ & $\mathrm{I} 1$ & $\mathrm{I} 1$ & $\mathrm{I} 2$ & $\mathrm{C}$ & $\mathrm{P} 1$ & $\mathrm{P} 2$ & $\mathrm{M} 1$ & $\mathrm{M} 2$ & $\mathrm{M} 3$ \\
\hline $\mathrm{M} 3$ & M2 & M1 & P2 & P1 & C & I2 & I1 & I1 & I2 & C & P1 & P2 & M1 & M2 & M3
\end{tabular}

There is incisor occlusal over-bite. The tooth crown surfaces are slightly worn (anterior teeth: score 2, molars: score 2), except for the third molars (score: 0), which were just beginning to erupt.

Postcranial skeleton: all the post cranial elements are in a good state of preservation. The upper limb bones include both scapulae, humeri, radii and ulnae and are nearly complete. The os coxae, femora and tibiae are nearly complete, but the fibulae are poorly preserved. The vertebrae, sacrum, and ribs are also well preserved. 


\section{MB05M 14:}

This burial consists of a near complete skeleton only missing the feet. Bone preservation is good. The skull was damaged only at the cranial base and full set of deciduous dentition has erupted.

\section{MB05M 15:}

Skull: incomplete due to missing a major part of the frontal bone. The calvarium is dolichocephalic (cranial index: 70.5) and the forehead is wide. Metopism is absent, but the supranasal suture is present. The glabella region, superciliary arches and nasal root are flat. The facial skeleton is high (upper facial height: $71 \mathrm{~mm}$ ), and the upper facial index is 53.4 (Martin No. 48:45), categorising this cranium as moderate, but somewhat narrower than average. Orbital shape is round and supraorbital foramina are bilaterally absent. The zygomatic bones display minimal lateral projection, while the temporal lines are not distinct on the parietal bones. The size of the mastoid process is moderate (score: 3 ), the external occipital protuberance is weakly developed (score: 2), but both the superior and inferior nuchal lines are distinct, although the nuchal plane is relatively smooth. The sagittal and lambdoidal sutures are not synostosed ectocranially. The coronal suture is not assessable due to postmortem damage. Endocranial synostosis is not assessable due to soil filling the endocranium. The mandibular body is gracile and compact. The pterygoid muscle attachment surfaces are smooth and the angles are not sharp. The rami slope steeply backwards, and the mental eminence is weak (score: 1). Dental preservation:

\begin{tabular}{cccccccc|cccccccc}
0 & M2 & M1 & 0 & 0 & 0 & 0 & 0 & 0 & 0 & C & P1 & 0 & M1 & M2 & X \\
\hline M3 & M2 & M1 & P2 & P1 & C & I2 & I1 & I1 & 0 & C & P1 & P2 & M1 & M2 & M3
\end{tabular}

The incisor occlusal pattern is unknown due to lack of the upper incisors. The tooth crown surfaces are moderately worn (anterior teeth: score 2, molars: score 34), except for the lower third molars (score: 0).

Postcranial skeleton: only the right clavicle and scapula, the upper right ribs and cervical vertebrae, a part of the right ulna, the right hand, the right femur, tibia and fibula and part of one foot are well preserved. Other bones are missing due to postburial disturbance. The femoral and tibial shafts and are not robust.

\section{MB05M 16a:}

Skull: partially preserved. The missing regions include the left parietal, cranial base, mandible and maxilla. This skull is characterised as possessing a robust, rugged and compact face. The calvarium is brachycephalic (cranial index: 85.6) and the forehead is narrow and slopes back steeply. The parietal bones are sharply angled at the sagittal suture. The supranasal suture is absent, the glabella region and medial portion of the superciliary arches prominently project and the nasal root is deeply concave. The orbital shape is square, with relatively straight margins and angled corners. The supraorbital foramen was absent on the right side at least; the left is unknown due to post-mortem damage. The zygomatic bones project prominently laterally and the temporal lines are distinct on the parietal bones. The size of the mastoid process is undetermined due to this region being absent. The 


\section{H. MATSUMURA ET AL.}

external occipital protuberance is well developed, but not greatly protruding (score: 3). Both the superior and inferior nuchal lines are quite distinct, but the nuchal plane is relatively smooth. The coronal, sagittal and lambdoidal sutures are unsynostosed ectocranially. Dental preservation:

\begin{tabular}{llllllll|llllllll}
1 & $/$ & $/$ & $/$ & $/$ & $/$ & $/$ & $/$ & $/$ & $/$ & $\mathrm{C}$ & $/$ & $/$ & $\mathrm{M} 1$ & $/$ & $/$ \\
\hline$/$ & $/$ & $/$ & $/$ & $/$ & $/$ & $/$ & $/$ & $/$ & $/$ & $/$ & $/$ & $/$ & $/$ & $/$ & $/$
\end{tabular}

The tooth crown surfaces are lightly worn (score: 2-3).

Postcranial skeleton: the lower leg below the knee was missing due to later disturbance of this burial. Apart from these missing portions, preservation is moderate. The upper limbs and femora are almost complete. The os coxae and vertebrae also remain intact. The dimensions of the limbs are moderate with well developed muscle attachment areas, including the linea aspera of the femora, and the deltoid tuberosity of the humerus.

\section{MB05M 16b:}

See entry in Appendix 1: $1 \mathrm{x}$ right maxillary $\mathrm{di}^{2}$ unerupted (crown only formed); 1 $\mathrm{x}$ right tibial diaphysis; $1 \mathrm{x}$ fibula diaphysis, $1 \mathrm{x}$ rib fragment, $2 \mathrm{x}$ vertebral arches.

\section{MB05M 17:}

A very poorly preserved assemblage of post-cranial fragments.

\section{MB05M 18:}

A nearly complete skeleton missing feet and hands (as well as right radius and ulna). All deciduous teeth except for the second deciduous molars are fully erupted.

\section{MB05M 19:}

A very poorly preserved skeleton. Only shaft segments of the femur, tibia, and fibula survived.

\section{MB05M20:}

Skull: very poor bone quality (extremely friable bone) meant that much of the cranium did not survive removal. Post-excavation the skull lacks its basicranium, including the occipital, sphenoid and temporal bones. The paired malar, zygomatic and nasal bones were also lost, but the cranium could be reconstructed. The cranium is gracile and the forehead is narrow. The parietal bones are weakly angled at the sagittal suture. The frontal has a slight posterior slope. The glabella region and superciliary arches are flat, and the orbital shape is rounded. Supraorbital foramina were absent bilaterally. The temporal lines are slightly distinct on the parietal bones. The mastoid process shows moderate size (score: 3 ) and the external occipital protuberance is moderately developed (score: 3). Although both the superior and inferior nuchal lines are distinct, the nuchal plane is smooth. The coronal, sagittal and lambdoidal sutures are un-synostosed both ecto and endocranially. The cranial index is 77.8 (Martin No. 8:1), indicating a mesocephalic cranium. The mandibular body is also gracile. The mental eminence is less than moderate (score 2), and the chin is pointed. The gonial region is not everted and the 
pterygoid muscle attachment surfaces are minimally developed. The wide rami is perpendicularly positioned. Dental preservation:

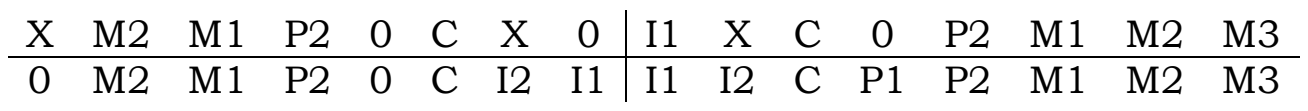

There is incisor occlusal edge-to-edge bite. The tooth crown surfaces are moderately worn (anterior teeth: score 4, molars: score 4-5), except for the third molars (score: 1 ).

Postcranial skeleton: the majority of postcranial remains are preserved and bone preservation is good, but condition is fragile, due to interment within the sand/shell matrix.

\section{MB05M21:}

The burial consists of a nearly complete skeleton. The long bones are nearly complete, with only the feet and right hand missing. The cranium was crushed laterally, but some portions of the calvarium have been reconstructed. The mandibular incisors are not yet fully erupted, while the maxillary central incisor crowns and deciduous molar crowns were calcified.

\section{MB05M22:}

Represented by fragments of a tibia and fibula, parts of an ulna, radius and hand, a femoral head, part of a patella and a few rib sections.

\section{MB05M23:}

This individual is represented by only the postcranial skeleton of a young infant. Bone condition is damp and fragile, but generally good. However, the skeleton was missing its head (due to intrusion of the grave shaft of MB05M24), hands, feet (except for a right tarsal), and the right humerus. No dentition was recovered.

\section{MB05M24:}

The bone condition is friable, but otherwise good. The skull and dentition are almost complete, with notable features being the eruption of the permanent maxillary and mandibular incisors and first molars, and the retention of the deciduous maxillary and mandibular molars and canines.

\section{MB05M25:}

An almost complete skeleton with good to excellent bone preservation. A full set of deciduous teeth has completely erupted and the permanent first molars are visible within their alveoli.

\section{MB05M26:}

Represented by a few cranial fragments and several deciduous teeth: left maxillary c, right maxillary $\mathrm{i}^{1}$, right maxillary $\mathrm{i}^{2}$ (see notes in Appendix 1).

\section{MB05M27:}

The right patella and fragments of the tibia and fibula of an otherwise 


\section{H. MATSUMURA ET AL.}

unexcavated burial.

\section{MB05M28:}

A partially preserved ( $1 / 2$ to $3 / 4$ of elements present in situ). The remains are in poor condition, extremely friable and excavated preserved sections included the right and left humeral shafts and the left femoral shaft. Some fragments of the left maxilla and mandible were recovered, including a few heavily worn teeth.

\section{MB05M29:}

Skull: almost complete, although the nasal bones were missing. The cranium is very robust, which differentiates it from most of the other skulls in the Man Bac assemblage. The glabella region and superciliary arches are remarkably prominent and every muscle attachment area is strongly developed. The forehead is narrow and prominently slopes backwards. The parietal bones are not angled at the sagittal suture and the zygomatic bones are large and prominently projecting laterally. The facial region is low and wide and the orbital margins are square, while the nasal root is deeply concave. The degree of dolichocephalism (cranial index: 74.2) and alveolar prognathism are remarkable. Supraorbital foramina are present bilaterally and the temporal lines are distinct on the parietal bones. The mastoid process is quite large (score: 5) and the external occipital protuberance is massive and protruding (score: 4). Both the superior and inferior nuchal lines are well-defined, with the nuchal plane being very rugged. The coronal, sagittal and lambdoidal sutures are not ectocranially synostosed (score: 0), but were not assessable endocranially. The upper facial index is 48.6 (Martin No. 48:45), categorising facial proportions into the low and broad category. The mandibular body is very robust, but the mental eminence is moderate (score 3 ). The gonial region is strongly everted bilaterally, with well developed attachment surfaces for the pterygoid muscle. The rami are very wide and gently slope backwards. Dental preservation:

\begin{tabular}{llllllll|llllllll} 
M3 & M2 & M1 & P2 & P1 & C & I2 & I1 & I1 & I2 & C & P1 & P2 & M1 & M2 & M3 \\
\hline M3 & M2 & M1 & P2 & P1 & C & I2 & I1 & I1 & I2 & C & P1 & P2 & M1 & M2 & M3
\end{tabular}

The incisor occlusal pattern is edge-to-edge type, and the tooth crown surfaces are remarkably worn (anterior teeth: score 5, molars: score 6-8).

Postcranial skeleton: very good preservation with only the distal half of the right tibia and fibula, and the right foot missing. The upper limb bones are robust, with well developed muscle attachment entheses.

\section{MB05M30:}

A nearly complete skeleton. The cranium was completely reconstructed, except for the parietal region. Full sets of long bones were recovered, but were damaged at the proximal and/or distal ends. Only the deciduous incisors have erupted to the level of half crown height.

\section{MB05M31:}

Skull: cranium (except for the base) and mandible are well preserved. The calvarium is brachyocephalic (cranial index: 88.6), with the forehead being 
somewhat narrow and vertical. The parietal bones are not angled at the sagittal suture and the supranasal suture is absent. The glabella region and superciliary arches are weakly ridged and the nasal root is rather flat. The facial region is very high (upper facial height: $74 \mathrm{~mm}$ ), but the facial index (50.7) is within the medium range. The orbital shape is round and supraorbital foramina are absent bilaterally. The zygomatic bones strongly project laterally. The temporal lines are not distinct on the parietal bones, the mastoid process is large (score: 4), and the external occipital protuberance is massive and prominent (score: 4). The superior and inferior nuchal lines are well-defined and the nuchal plane is rugged. The coronal and lambdoidal sutures have not synostosed either ecto or endocranially, while the sagittal suture is partially synostosed ecto and endocranially. The mandibular body is robust, but the mental eminence is weak (score 2). The gonial angles are weakly everted and the pterygoid muscle attachment surfaces are well developed. The rami slightly slope posteriorly. Dental preservation:

\begin{tabular}{cccccccc|cccccccc}
$\mathrm{X}$ & $\mathrm{M} 2$ & $\mathrm{M} 1$ & $\mathrm{P} 2$ & $\mathrm{P} 1$ & $\mathrm{C}$ & $\mathrm{X}$ & 0 & 0 & $\mathrm{X}$ & $\mathrm{C}$ & $\mathrm{P} 1$ & $\mathrm{P} 2$ & $\mathrm{M} 1$ & $\mathrm{M} 2$ & $\mathrm{M} 3$ \\
\hline $\mathrm{M} 3$ & $\mathrm{M} 2$ & $\mathrm{M} 1$ & $\mathrm{P} 2$ & $\mathrm{P} 1$ & $\mathrm{C}$ & 0 & $/$ & 0 & 0 & $\mathrm{C}$ & $\mathrm{P} 1$ & $\mathrm{P} 2$ & $\mathrm{M} 1$ & $\mathrm{M} 2$ & M3
\end{tabular}

The incisor occlusal pattern was indeterminate and the tooth crown surfaces are remarkably worn (anterior teeth: score 5, molars: score 5, except for the third molars (score: 3).

Postcranial skeleton: preservation condition is good. The upper and lower appendicular elements on the left side are in a better state of preservation than those on the right. The humeri, radii, ulnae, os coxae, femora, and tibiae are all almost complete. The vertebrae, sacrum and ribs are also well preserved.

\section{MB05M32:}

Only a relatively thick calvarium with a large mastoid process, a robust mandible and some fragments of the humeral shaft represent this burial. Dental preservation:

\begin{tabular}{cccccccc|cccccccc}
$/$ & $/$ & $\mathrm{M} 1$ & $\mathrm{P} 2$ & $\mathrm{P} 1$ & $/$ & $/$ & $\mathrm{I} 1$ & $/$ & $/$ & $/$ & $/$ & $/$ & $/$ & $/$ & $/$ \\
\hline$/$ & $/$ & $/$ & $/$ & $/$ & $/$ & $/$ & $/$ & 0 & 0 & 0 & $\mathrm{P} 1$ & $\mathrm{P} 2$ & $\mathrm{M} 1$ & $\mathrm{M} 2$ & $\mathrm{M} 3$
\end{tabular}

The tooth crown surfaces are moderately worn (score: 3-4, except the third molars (score: 1).

\section{MB05M33:}

Unused burial identification number.

\section{MB05M34:}

Skull: the zygomatico-facial region was heavily damaged, but the calvarium and the mandible are in relatively good condition. The forehead is relatively broad and only slightly sloped. The parietal bones are smoothly rounded at the sagittal suture and the supranasal suture is absent. The glabella region and superciliary arches are flat. The superior orbital margin at the frontal bone is quite round and a supraorbital foramen is present on the right side alone. The temporal lines are not visible at all on the parietal surface. The mastoid process is small (score: 2) and the 


\section{H. MATSUMURA ET AL.}

external occipital protuberance is flat (score: 1). Both superior nuchal lines are definable. The inferior one is not observable due to the fragmentation of this region, but the nuchal plane is quite smooth. The coronal, sagittal and lambdoidal sutures are not synostosed either ecto or endocranially. The mandibular body is gracile and small, with a weak mental eminence (score 2). The gonial angles are not sharply everted and the pterygoid muscle attachment surfaces are smooth. The rami are narrow and moderately sloping posteriorly. The base line of the mandibular body is slightly curved, indicating the 'rocker jaw' variant, despite being a compact mandible. Dental preservation:

\begin{tabular}{lccccccc|cccccccc}
$/$ & $/$ & M1 & P2 & P1 & C & X & I1 & I1 & X & C & P1 & P2 & M1 & $/$ & $/$ \\
\hline $\mathrm{X}$ & M2 & X & P2 & P1 & C & I2 & I1 & I1 & I2 & C & P1 & P2 & X & X & X
\end{tabular}

The incisor occlusal pattern is indeterminate, while the tooth crown surfaces are remarkably worn (score: 5), for both the anterior and posterior teeth.

Postcranial skeleton: only the left hand is missing. Most limb bones are in a good state of preservation, although some sections were damaged. All upper limb elements, and those of the right leg, were complete. Their size and robustness, including development of muscle attachment entheses, are within the average range for females. Although preservation of the vertebrae and ribs is poor, the sacrum and lumbar vertebrae are in relatively good condition.

\section{MB05M35:}

Unexcavated burial. No data available.

\section{MB05M36:}

A partially preserved skeleton. The cranium and mandible are fragmentary, the left leg is missing below the femoral diaphysis and the right leg is missing below the tibial and fibular diaphyses. The mandibular body and part of the maxilla are intact, with a full set of completely erupted deciduous teeth.

\section{HUMAN REMAINS FROM THE 2007 SERIES}

\section{H1}

\section{MB07H1M1:}

Skull: moderately well preserved, although it has been deformed by soil pressure over time. The fragile basicranium and the right side of the face were fragmented. Slight dental attrition is observed in the permanent central incisors (score: 1), while the other permanent teeth are newly erupted. The left maxilla retains the deciduous second molar, without the roots, situated between the first premolar and the first molar, under which the second premolar is emerging. Dental preservation:

\begin{tabular}{llllllll|llllllll}
$\mathrm{X}$ & $\mathrm{M} 2$ & $\mathrm{M} 1$ & $\mathrm{P} 2$ & $\mathrm{P} 1$ & $\mathrm{C}$ & $\mathrm{I} 2$ & $\mathrm{I} 1$ & $\mathrm{I} 1$ & $\mathrm{I} 2$ & $\mathrm{C}$ & $\mathrm{P} 1$ & $\mathrm{P} 2$ & $\mathrm{M} 1$ & $\mathrm{M} 2$ & $\mathrm{M} 3$ \\
\hline $\mathrm{X}$ & $\mathrm{M} 2$ & $\mathrm{M} 1$ & $\mathrm{P} 2$ & $\mathrm{P} 1$ & $\mathrm{C}$ & $\mathrm{I} 2$ & $\mathrm{I} 1$ & $\mathrm{I} 1$ & $\mathrm{I} 2$ & $\mathrm{C}$ & $\mathrm{P} 1$ & $\mathrm{P} 2$ & $\mathrm{M} 1$ & $\mathrm{M} 2$ & $\mathrm{M} 3$
\end{tabular}


Postcranial skeleton: The postcranial skeleton is in relatively good condition, but the upper limbs, vertebrae and ribs were highly degraded. The entire left arm is missing, as is the right hand and proximal ulna/radius.

\section{MB07H1M2:}

Only the proximal half of a tibia and associated fibula fragment represent this burial. No dentition is present.

\section{MB07H1M3:}

Skull: The cranium was damaged only at the maxillo-frontal processes. Dental preservation:

\begin{tabular}{llllllll|llllllll}
$\mathrm{X}$ & $\mathrm{M} 2$ & $\mathrm{M} 1$ & $\mathrm{P} 2$ & $\mathrm{P} 1$ & $\mathrm{C}$ & $\mathrm{I} 2$ & $\mathrm{I} 1$ & $\mathrm{I} 1$ & $\mathrm{I} 2$ & $\mathrm{C}$ & $\mathrm{P} 1$ & $\mathrm{P} 2$ & $\mathrm{M} 1$ & $\mathrm{M} 2$ & $\mathrm{M} 3$ \\
\hline $\mathrm{X}$ & M2 & M1 & P2 & P1 & C & I2 & I1 & I1 & I2 & C & P1 & P2 & M1 & M2 & M3
\end{tabular}

The central incisors and first molars are slightly worn (score: 2), while no wear facets are visible for the other permanent teeth.

Postcranial skeleton: Most of the postcranial bones remain and only a few cranial fragments and distal tarsal and carpal phalanges are missing.

\section{MB07H1M4:}

Skull: well preserved, but the facial region is highly fragmented. Only the calvarium and the mandible are complete. The calvarium is brachycephalic (cranial index: 81.3), the forehead is narrow and slopes posteriorly. The parietal bones are minimally angled at the sagittal suture. The supranasal suture is absent. The glabella region is moderately protruding, but the superciliary arches are flat. The nasal root is concave and the orbital shape is square with relatively angular corners. Supraorbital foramina are absent bilaterally. The zygomatic bones project prominently laterally and the temporal lines are not distinct on the parietal bones. The size of the mastoid process is rather small (score: 2). The external occipital protuberance is weakly protruding (score: 2), while both superior and inferior nuchal lines are distinct, and the nuchal plane is moderately rugged. The coronal, sagittal and lambdoidal sutures are not synostosed either ecto or endocranially. The mandibular body is relatively robust, with sharply everted gonial angles, developed pterygoid muscle attachment surfaces, and weakly sloping rami. The mental eminence is moderately protruding (score: 3 ). Dental preservation:

\begin{tabular}{cccccccc|cccccccc}
$\mathrm{X}$ & $\mathrm{X}$ & $\mathrm{M} 1$ & $\mathrm{P} 2$ & $/$ & $\mathrm{C}$ & $\mathrm{X}$ & $\mathrm{I} 1$ & $\mathrm{I} 1$ & $\mathrm{X}$ & $\mathrm{C}$ & $\mathrm{P} 1$ & $\mathrm{X}$ & $/$ & $/$ & $/$ \\
\hline $\mathrm{M} 3$ & 0 & $\mathrm{M} 1$ & $\mathrm{P} 2$ & $\mathrm{P} 1$ & $\mathrm{C}$ & $\mathrm{X}$ & $\mathrm{X}$ & $\mathrm{X}$ & $\mathrm{X}$ & $\mathrm{C}$ & $\mathrm{P} 1$ & $\mathrm{P} 2$ & $\mathrm{M} 1$ & $\mathrm{M} 2$ & $\mathrm{M} 3$
\end{tabular}

The tooth crown surfaces are heavily worn overall (anterior teeth: score 5, molars: score 6-7).

Postcranial skeleton: In situ preservation was good, although bone quality was 


\section{H. MATSUMURA ET AL.}

poor leading to fragmentation on removal. Limb bone sizes are moderate and display well-developed muscle attachment entheses, including the deltoid area of the humerus and the femoral linea aspera. Squatting facets are present on the talus.

\section{MB07H1M5:}

Skull: almost complete, and the overall dimensions are robust. The shape of the calvaria is classified as brachyocephalic (cranial index: 80.1). The parietal bones are weakly angled at the sagittal suture and the frontal displays a strong posterior slope. The supranasal suture is absent, the glabella region and superciliary arches are moderately ridged and the nasal root is slightly concave. The orbital shape is rather square with straight frontal margins. Supraorbital foramina are absent bilaterally and the zygomatic bones project prominently laterally. The facial skeleton is relatively low and wide, but the index is within the range of moderate facial proportions (upper facial index: 51.9), while the temporal lines are not distinct on the parietal bones. The mastoid process is quite large (score: 4), while the external occipital protuberance is weakly protruding. The superior and inferior nuchal lines are distinctive and the nuchal plane is moderately ridged. The coronal, sagittal and lambdoidal sutures are not synostosed ectocranially externally, while the endocranium could not be assessed. The mandible is robust, displaying sharply everted gonial angles and well-developed pterygoid muscle attachment surfaces. The rami are minimally sloping, and the baseline of the mandibular body is rounded, typical of the 'rocker jaw' variant. The mental eminence is moderately protruding (score: 3). Dental preservation:

\begin{tabular}{cccccccc|cccccccc}
0 & M2 & M1 & P2 & P1 & C & X & I1 & I1 & X & C & P1 & P2 & M1 & M2 & M3 \\
\hline M3 & M2 & M1 & P2 & P1 & C & X & X & X & X & C & P1 & P2 & M1 & M2 & X
\end{tabular}

All the crown surfaces are heavily worn (anterior teeth: score 6, molars: score 7).

Postcranial skeleton: all elements are in a good state of preservation. Paired upper limb bones include the scapulae, humeri, radii and ulnae, and all are nearly complete. The os coxae, femora, tibiae, fibulae and patellae of both sides are also almost complete. The deltoid muscle attachment area of humerus is large and robust. Well developed leg muscles are presumed from the overall femoral morphology, specifically the highly curved shaft and strongly protruding linea aspera. The vertebrae, sacrum and ribs also remain in good condition.

\section{MB07H1M6:}

The cranium and mandible are well preserved, except for the fragmentary facial region. Most of the postcranial skeleton was recovered in good condition as well, although both feet and hands are missing (except for a few disarticulated proximal phalanges), as are many ribs. All deciduous tooth crowns were completely formed within the alveoli, but not yet erupted.

\section{MB07H1M7:}

The preservation of the cranium and mandible are very poor. Only the left maxilla 
is nearly complete. The upper first deciduous molars are visible at $2 / 3$ crown height within the alveolus. Only the lumbar vertebrae, os coxae and lower limbs (feet missing) are preserved due to the disturbance caused by the later burial of MB07H1M3.

\section{MB07H1M8:}

Skull: nearly complete, with robust cranial morphology. The parietal bones are weakly angled at the sagittal suture, and the frontal slopes steeply. The glabella region and superciliary arches are moderately ridged, while the orbital shape is squared with straight orbital margins. Supraorbital foramina were absent bilaterally. The temporal lines are slightly visible on the parietal bones. The mastoid processes are prominent (score: 5). The external occipital protuberance is also prominently projecting (score: 4). The superior nuchal line is distinct, but the inferior one is not and the nuchal plane is smooth. The coronal, sagittal and lambdoidal sutures are not synostosed either ecto or endocranially. The mandibular body is of moderate size and robusticity, while the mental eminence is moderately expressed (score 3) and the tri-angular region is clear. The gonial angles are not everted and the pterygoid muscle attachment surfaces are weakly developed. The wide rami are perpendicularly elevated and the baseline of the mandibular body is strongly curved, exhibiting the 'rocker jaw' variant. Dental preservation:

\begin{tabular}{llllllll|llllllll} 
M3 & M2 & M1 & P2 & P1 & C & X & I1 & I1 & I2 & C & P1 & P2 & M1 & M2 & M3 \\
\hline M3 & M2 & M1 & P2 & P1 & C & I2 & I1 & I1 & I2 & C & P1 & P2 & M1 & M2 & M3
\end{tabular}

There is an edge-to-edge incisor occlusal bite. The tooth crown surfaces are moderately worn (anterior teeth score: 4 , molars score: 5 except for the third molars score: 3).

Postcranial skeleton: the limb bones are in a good state of preservation. The humeri, radii and ulnae are complete, but the scapulae are only partially preserved. The femora, tibiae and fibulae are also complete, while the os coxae were fragmentary. The dimensions of these limb bones are moderate and relatively slender. All the muscle attachment areas are smooth and minimally developed. Much of the vertebrae are in good condition. A clear squatting facet is present on the talus.

\section{MB07H1M9:}

Skull: cranium and mandible are well preserved, except for the basicranium and a section of the zygomatico-facial skeleton. The calvarium is quite long and narrow (cranial index: 72.9) or dolichocephalic. The forehead is also narrow and minimally sloping. The parietal bones are moderately angled at the sagittal, while the supranasal suture is absent. The glabella region is flat, while the superciliary arches are weakly ridged at their medial extent. The orbital shape is slightly rounded. A supraorbital foramen is present on the left side alone. The zygomatic bones are moderately projecting laterally. The temporal lines are not distinct on the parietal bones. The mastoid process is large (score: 5), and the external occipital protuberance is massive and prominent (score: 5). The superior nuchal lines are well-defined, but the inferior is not as ridged as the superior and the nuchal plane 


\section{H. MATSUMURA ET AL.}

is smooth. The sagittal, coronal, and lambdoidal sutures have not synostosed either ecto or endocranially. A large Inca bone subdivides the occipital region. The mandibular body is large and robust, with a well developed mental eminence (score 4). However, the gonial angles are not everted, but the pterygoid muscle attachment surfaces are well developed. The rami do not slope backwards and the mandibular body exhibits the 'rocker jaw' variant with a strongly curved baseline. Dental preservation:

\begin{tabular}{cccccccc|cccccccc} 
M3 & M2 & M1 & P2 & P1 & C & I2 & I1 & I1 & 0 & C & P1 & P2 & M1 & M2 & M3 \\
\hline$/$ & M2 & M1 & P2 & P1 & C & $/$ & $/$ & 0 & I2 & C & P1 & P2 & M1 & M2 & M3
\end{tabular}

The incisor occlusal bite is edge to edge, while the occlusal surfaces were not severely worn (score: 4 anterior teeth, score 4-5 first and second molars, score 2 third molars).

Postcranial skeleton: unfortunately, the lower thoracic region, including most ribs and the lumbar vertebrae did not survive. The limbs, with the exception of the left arm, are variously preserved. A range of pathological conditions are apparent, including extensive lower limb atrophy and a completely ankylosed cervical spine (see Oxenham et al. 2009).

\section{MB07H1M10}

Skull: damaged at the zygomatico-facial region and basicranium, although the calvaria and mandible are well preserved. The forehead of the frontal bone is narrow and the cranial vault is mesocephalic (cranial index: 77.4$)$. The parietal bones are not angled at the sagittal suture and the superciliary arches are moderately ridged anteriorly. The frontal bone has a slight slope, while the supranasal suture is absent. The glabella region and the nasal root are flat, the orbital margins are round and supraorbital foramina are absent bilaterally. The temporal lines are not distinct on the parietal bones. The mastoid processes are of moderate size (score: 3), while the external occipital protuberance is not protruding. The degree of development of the superior and inferior nuchal lines are unknown due to postmortem damage. The coronal, sagittal and lambdoidal sutures display nearly complete synostosis both ecto and endocranially. The mandibular body is large but gracile, with minimally developed pterygoid muscle attachment surfaces and rami that have a marked posterior slope. The mental eminence is moderately protruding (score: 3). Dental preservation:

\begin{tabular}{llllllll|llllllll}
$\mathrm{X}$ & $\mathrm{X}$ & $\mathrm{M} 1$ & $\mathrm{P} 2$ & $\mathrm{P} 1$ & $\mathrm{C}$ & $\mathrm{X}$ & $\mathrm{I} 1$ & $\mathrm{I} 1$ & $\mathrm{X}$ & $\mathrm{C}$ & $\mathrm{P} 1$ & $\mathrm{P} 2$ & $\mathrm{M} 1$ & $\mathrm{M} 2$ & $\mathrm{X}$ \\
\hline $\mathrm{X}$ & 0 & $\mathrm{M} 1$ & $\mathrm{P} 2$ & $\mathrm{P} 1$ & $\mathrm{C}$ & $\mathrm{I} 2$ & $\mathrm{I} 1$ & $\mathrm{I} 1$ & $\mathrm{I} 2$ & $\mathrm{C}$ & $\mathrm{P} 1$ & $\mathrm{P} 2$ & $\mathrm{M} 1$ & $\mathrm{M} 2$ & 0
\end{tabular}

The occlusal surfaces are heavily worn (anterior teeth: score 5, molars: score 5-6). Postcranial skeleton: moderately well preserved. The humeri, radii and ulnae are nearly complete, except for the humeral heads; however, the scapulae were quite fragmentary. The femora, tibiae, fibulae and patellae on both sides are also well preserved, except for the distal condyles of the femora. The muscle attachment areas of the lower limbs, including the pilastric form of the linea aspera of the femora, are moderate, whereas the deltoid tuberosity of the humerus is well 
developed. The vertebrae are highly fragmented.

\section{MB07H1M11:}

Skull: nearly complete and intact, only small sections of the zygomaxillary and basicranial regions were damaged. The calvaria is mesocephalic (cranial index: 76.1), with a wide forehead. The supranasal suture is absent and the glabella region, superciliary arches and nasal root are all remarkably flat, with minimally elevated nasal bones. The orbital shape is slightly round and a supraorbital foramen is present on the left side only. The zygomatic bones are moderately projecting laterally. The temporal lines are not distinct on the parietal bones and the size of the mastoid process is moderate (score: 3). The external occipital protuberance is slightly ridged (score: 2) and the superior nuchal lines are indistinct, with the inferior line being unobservable due to postmortem damage. The nuchal plane is quite smooth. The coronal, sagittal and lambdoidal sutures are not synostosed either ecto or endocranially. The width/height ratio of the facial region is moderate as indicated by a facial index of 52.2. The mandibular body is relatively gracile and compact. The pterygoid muscle attachment surfaces are smooth, the gonial angles are not everted and the rami are minimally sloping. The mental eminence is moderate (score: 3 ), despite the small mandibular body. The baseline of the mandibular body is straight. Dental preservation:

\begin{tabular}{cccccccc|cccccccc}
$/$ & $/$ & $/$ & 0 & 0 & 0 & $\mathrm{X}$ & 0 & $\mathrm{I} 1$ & $\mathrm{X}$ & 0 & $\mathrm{P} 1$ & 0 & $\mathrm{M} 1$ & $\mathrm{M} 2$ & $\mathrm{M} 3$ \\
\hline $\mathrm{X}$ & $\mathrm{X}$ & $\mathrm{M} 1$ & $\mathrm{P} 2$ & $\mathrm{P} 1$ & $\mathrm{C}$ & $\mathrm{X}$ & $\mathrm{X}$ & $\mathrm{X}$ & $\mathrm{X}$ & 0 & $\mathrm{P} 1$ & $\mathrm{P} 2$ & $\mathrm{M} 1$ & $\mathrm{X}$ & $\mathrm{X}$
\end{tabular}

Incisor occlusal pattern not assessable. The tooth crown surfaces are heavily worn (anterior teeth score: 5, molars score: 5-7), with the left mandibular molars especially reaching a severe stage of attrition (score: 7 ).

Postcranial skeleton: most postcranial elements are nearly complete. The size and development of muscle attachment regions are moderate. Clear squatting facets are visible on both tali.

\section{MB07H1M12:}

The cranium is crushed and mostly missing, and most preserved elements (ribs, left os coxa, clavicles, scapulae, right humerus, left proximal femur, cervical and thoracic vertebrae) are disarticulated.

\section{MB07H1M13a:}

Skull: the cranium is absent, but a mandible of appropriate age and dimensions was recovered in level 15(III), square A1H2. The mandibular body is relatively large and robust. The base line is prominently curved, indicating a clear 'rocker jaw' variant. The pterygoid muscle attachment surfaces are well developed, despite the minimally everted gonial angles. The rami are wide and minimally angled. The mental eminence is prominent (score: 4). Dental preservation:

\begin{tabular}{cccccccc|cccccccc}
$/$ & $/$ & $/$ & $/$ & $/$ & $/$ & $/$ & $/$ & $/$ & $/$ & $/$ & $/$ & $/$ & $/$ & $/$ & $/$ \\
\hline $\mathrm{X}$ & $\mathrm{X}$ & $\mathrm{M} 1$ & $\mathrm{P} 2$ & $\mathrm{P} 1$ & $\mathrm{C}$ & $\mathrm{I} 2$ & $\mathrm{I} 1$ & $\mathrm{I} 1$ & $\mathrm{I} 2$ & $\mathrm{C}$ & $\mathrm{P} 1$ & $\mathrm{P} 2$ & $\mathrm{M} 1$ & $\mathrm{M} 2$ & $\mathrm{M} 3$
\end{tabular}




\section{H. MATSUMURA ET AL.}

All elements above the radius/ulna are either missing or disarticulated, with the exception of the middle thoracic vertebrae and four ribs. The cranium is absent, but a mandible of appropriate age and dimensions was recovered in level 15(III), square A1H2. Both hands and feet are intact and in situ.

The attrition of the occlusal surfaces is severe (anterior teeth score: 5, first and second molars score: 5-7, third molars score 5).

Postcranial skeleton: Only the appendicular bones are well preserved, though generally incomplete. The os coxae, most vertebrae, and the ribs were recovered highly fragmented. The diaphyses that remain are slender, suggestive of weakly developed muscle attachment areas, although the linea aspera are prominently ridged. Clear squatting facets are present on the talus.

\section{MB07H1M13b:}

See Appendix 1 entry.

\section{MB07H1M14a}

See Appendix 1 entry.

\section{$\underline{2007 H 2}$}

MB07H2M1 Age: middle-aged adult. Sex: male.

Skull: nearly complete, with a robust cranial morphology overall. The cranial index is 85.2 (Martin No. 8:1), indicating a brachyocephalic cranium. The upper facial index is 48.4 (Martin No. 48:45), indicating low and wide facial proportions. The parietal bones are moderately angled at the sagittal suture and the frontal slopes steeply. The glabella region and superciliary arches are strongly ridged (score: 4), the orbital shape is square and the orbital margins are straight. A supraorbital foramen is present on the right orbit only. The temporal lines are clearly visible on the parietal bones. The size of the mastoid processes are moderate (score: 3). The external occipital protuberance is extremely prominent (score: 5), while both the superior and inferior nuchal lines are distinct, associated with a rugged nuchal plane. The coronal sutures are not synostosed either ecto or endocranially, while the sagittal and lambdoidal sutures are partially synostosed both ecto and endocranially. The mandibular body is large and robust. The mental eminence is moderate expressed (score: 3), with a distinctive triangular shape on the superior surface. The gonial angles are sharply everted and the pterygoid muscle attachment surfaces are rugged. The mandibular rami are wide and perpendicularly oriented. The baseline of the mandibular body is moderately curved, exhibiting the 'rocker jaw' variant. Dental preservation:

\begin{tabular}{clllllll|llllllll} 
M3 & M2 & M1 & P2 & P1 & C & I2 & I1 & I1 & I2 & C & P1 & P2 & M1 & M2 & M3 \\
\hline X & M2 & M1 & P2 & P1 & C & X & X & X & X & C & P1 & P2 & M1 & M2 & X
\end{tabular}

Incisor occlusal bite could not be assessed. The occlusal surfaces were moderately worn (anterior teeth score: 4-5, molars score: 6).

Postcranial skeleton: all postcranial elements were recovered in good condition. The humeri, radii and ulnae are complete, but the scapulae are fragmentary. The os 
coxae, femora, tibiae and fibulae are complete, except for postmortem damage around the knee joint. The dimensions of these limb bones are moderate and relatively slender, with all major muscle attachment areas being relatively smooth. Almost all vertebrae are in good condition. The tali exhibit clear squatting facets.

\section{MB07H2M2:}

Skull: well-preserved and gracile, with a perpendicularly elevated forehead and parietal bones not angled at the sagittal suture. The supranasal suture is absent and the glabella region, superciliary arches and nasal root are very flat. The orbital shape is more square than round and supraorbital foramina are present bilaterally. The zygomatic bones are relatively forward projecting, forming a generally flat face, together with a quite flat nasal root. Dental preservation:

\begin{tabular}{cccccccc|cccccccc}
$\mathrm{X}$ & $\mathrm{M} 2$ & $\mathrm{M} 1$ & $\mathrm{P} 2$ & $\mathrm{P} 1$ & $\mathrm{C}$ & I2 & I1 & I1 & I2 & C & P1 & P2 & M1 & M2 & X \\
\hline M3 & M2 & M1 & P2 & P1 & C & I2 & I1 & I1 & I2 & C & P1 & P2 & M1 & M2 & M3
\end{tabular}

The occlusal surfaces are slightly worn (anterior teeth: score 1, molars: score 1), except for the third molars (score: 2).

Postcranial skeleton: all postcranial elements are in good condition. The scapulae, humeri, radii and ulnae are nearly complete, as are the os coxae, femora and tibiae, whereas the fibulae are incomplete.

\section{MB07H2M3:}

Poorly preserved in general. All of the upper body is missing, almost all of the skull, the right tibia/fibula, most of both os coxae, both hands and feet are missing.

\section{MB07H2M4:}

Only the limb bones were recovered and these of right side alone.

\section{MB07H2M5:}

Skull: Except for a high degree of damage to some sections of the parietal and frontal bones, the skull was relatively well preserved, including a nearly complete zygomatico-facial region. The cranial index is 76.4 (Martin No. 8:1), indicating a mesocephalic cranium. The forehead is relatively broad, flat and elevated perpendicularly. The parietal bones are not angled and are smoothly rounded at the sagittal suture. A metopic suture is present. The glabella region, superciliary arches, nasal root and nasal bones are very flat. The superior orbital margin of the frontal bone is weakly rounded, while a supraorbital foramen of the 'notch' type is present on the right side; the left side being unknown due to post-mortem damage. The temporal lines are not visible at all on the parietal bones and the mastoid processes are quite small (score: 1). The external occipital protuberance is very flat (score: 1), and the nuchal plane, including both the superior and inferior nuchal lines, are weak and smooth. The coronal, sagittal and lambdoidal sutures are not synostosed ectocranially, and are not assessable endocranially. The facial skeleton is quite low and wide (upper facial height: $64 \mathrm{~mm}$, the upper facial index: 48.0). The 


\section{H. MATSUMURA ET AL.}

mandibular body is gracile and relatively small, but the mental eminence is prominent (score: 2). The gonial angles are not everted, the pterygoid muscle attachment surfaces are smooth and the rami are narrow and steeply sloping. The baseline of the mandibular body is remarkably curved, exhibiting pronounced 'rocker jaw,' despite the compact mandible. Preserved dentition:

\begin{tabular}{cccccccc|cccccccc}
0 & M2 & M1 & P2 & P1 & C & I2 & I1 & I1 & 0 & C & P1 & P2 & M1 & M2 & 0 \\
\hline 0 & M2 & M1 & P2 & P1 & C & I2 & I1 & I1 & I2 & C & P1 & P2 & M1 & 0 & X
\end{tabular}

The incisor occlusal pattern displays an over-bite. The occlusal surfaces are moderately worn (score: 5 for both the anterior and posterior teeth, except for the first molars, scored as 7).

Postcranial skeleton: A nearly complete skeleton postcranial skeleton. The distal $4 / 5$ ths of the right and left tibia and left fibula, distal $1 / 3^{\text {rd }}$ of the right fibula, all of the left tarsals and tarsal phalanges, and the right calcaneus and distal tarsal phalanges are missing. The left hand is disarticulated and scattered underneath the os coxae. Weak development of the muscle attachment regions generally.

\section{MB07H2M6:}

The cranium and most postcranial elements are well preserved, except for the fragmentary facial region. All deciduous tooth crowns are completely formed.

\section{MB07H2M7:}

The entire skeleton is in good condition, although the cranium was deformed by soil pressure and the facial skeleton was crushed into small fragments. The postcranial skeleton, including all four limbs, is nearly complete. Full eruption of the deciduous teeth was observed.

\section{MB07H2M8:}

Good skeletal preservation. Only the distal left and right tibiae and fibulae, both feet, and distal phalanges from both hands are missing. All teeth are deciduous, and right deciduous $\mathrm{m}^{1}$ was observed to be erupting.

\section{MB07H2M9:}

Poorly preserved skeleton. Only the left half of the cranium, the right ulna, distal radius, os coxae, one half of an un-sided femur, and a few rib fragments were recovered.

\section{MB07H2M10}

Skull: The skull is nearly complete, except for the heavily damaged left side of the face. This cranium is relatively large and robust, but the glabella and nasal region are quite flat. The cranial index is 77.9 (Martin No. 8:1), or mesocephalic. The upper facial index is 54.1 (Martin No. 48:45), categorizing the proportion of facial height to breadth as medium. The forehead is broad and steeply sloping. The parietal bones are sharply angled at the sagittal suture. The supranasal suture is absent, the superciliary arches are not protruding and the orbital shape is slightly rounded. Supraorbital foramina ('notch' variant) are present bilaterally. The zygomatic bones 
project prominently laterally and the temporal lines are distinct on the parietal bones. The size of the mastoid process is large (score: 4), the nuchal crest is weakly protruding (score: 5 ) and both the superior and inferior nuchal lines are distinct, on a moderately rugged nuchal plane. The coronal, sagittal and lambdoidal sutures are partially synostosed ectocranially, while they cannot be assessed endocranially. The mandibular body is large and robust, exhibiting strongly everted gonial angles and well developed pterygoid muscle attachment surfaces. The rami are rather narrow and moderately sloping. The mental eminence is moderately protruding (score: 3 ). Dental preservation:

\begin{tabular}{cccccccc|cccccccc} 
M3 & M2 & M1 & P2 & P1 & C & I2 & 0 & $/$ & $/$ & $/$ & $/$ & $/$ & M1 & M2 & 0 \\
\hline M3 & M2 & M1 & P2 & P1 & C & I2 & I1 & I1 & 0 & C & 0 & P2 & M1 & M2 & 0
\end{tabular}

The incisor occlusal pattern is an edge to edge-bite. Occlusal wear is severe (anterior teeth: score 5, molars: score 6-7).

Postcranial skeleton: all postcranial elements are in good condition. The scapulae, humeri, radii and ulnae are nearly complete, as are the os coxae, femora, tibiae, fibulae and patellae. The deltoid muscle enthesis of the humerus is robust, as are the major leg muscle entheses, associated with the well developed pilastric form of the femoral linea asperae and prominently curved femoral shafts. The vertebrae, sacrum and ribs also remain in good condition.

\section{MB07H2M11:}

See Appendix 1 entry.

\section{MB07H2M12:}

Skull: The cranium and mandible are nearly complete, except for the basicranial region. The overall view of this specimen is of a small and gracile individual. The calvarium is dolichocephalic (cranial index: 72.2), the forehead is narrow and sloped and the parietal bones are moderately angled. Presence of the supranasal suture is unknown, due to post-mortem damage to the supranasal region. The glabella, supraorbital ridges and nasal bones, including the root, are very flat (supraorbital ridge score: 2), while the superior orbital margins are slightly round. A supraorbital foramen is present bilaterally and the temporal lines are faintly traceable on the parietal surfaces. The mastoid processes are small (score: 1), and the external occipital protuberance is weakly ridged (score: 2). Both the superior and inferior nuchal lines are definable, although the nuchal plane is smooth. The coronal, sagittal and lambdoidal sutures exhibit minimal synostosis ectocranially. Endocranial synostosis is minimal at the coronal suture, but almost complete at sagittal and lambdoidal sutures. The upper facial height is relatively high (the height is $68 \mathrm{~mm}$ ). The mandibular body is gracile and small, with a weak mental eminence (score 2). The gonial angles are not everted and the pterygoid muscle attachment surfaces are smooth. The rami are narrow and moderately sloping. The baseline of the mandibular body is slightly curved, exhibiting the 'rocker jaw' variant, despite the compact mandible. Dental preservation: 
H. MATSUMURA ET AL.

\begin{tabular}{cccccccc|cccccccc}
$\mathrm{X}$ & $\mathrm{X}$ & $\mathrm{X}$ & $\mathrm{P} 2$ & $\mathrm{P} 1$ & $\mathrm{C}$ & $\mathrm{X}$ & $\mathrm{X}$ & $\mathrm{X}$ & 0 & 0 & $\mathrm{X}$ & $/$ & $/$ & $/$ & $/$ \\
\hline $\mathrm{X}$ & $\mathrm{X}$ & $\mathrm{X}$ & $\mathrm{X}$ & $\mathrm{P} 1$ & $\mathrm{C}$ & $\mathrm{X}$ & $\mathrm{X}$ & $\mathrm{X}$ & $\mathrm{X}$ & $\mathrm{C}$ & $\mathrm{P} 1$ & $\mathrm{P} 2$ & $\mathrm{M} 1$ & $\mathrm{X}$ & $\mathrm{X}$
\end{tabular}

The incisor occlusal pattern is not assessable. The occlusal surfaces are severely worn for the anterior teeth (score: 6), while wear of the left premolars and first molar are minimal (score: 3 ).

Postcranial skeleton: All postcranial elements are in good condition, although some sections suffered minimal damage. The limbs are moderate in length but slender, with muscle attachment sites being relatively smooth. The preservation level of the vertebrae and ribs is high.

\section{MB07H2M13:}

Preservation condition is good, with much of the skeleton (except the right os coxae, femur, tibia, fibula, tarsals, metatarsals and phalanges) remaining, including the skull and the complete facial region. All deciduous molars have erupted and show some wear.

\section{MB07H2M14:}

A partially preserved, fragile skeleton. The entire right arm, right tibia and both feet and hands are missing, and those elements present are moderately disarticulated The cranium is fragmented and no teeth have yet erupted in the near complete maxilla and mandible.

\section{MB07H2M15:}

A nearly complete and well preserved skeleton with only the proximal left ulna/radius, right tibial diaphysis and a few carpal phalanges missing. A full set of deciduous molars has erupted, with faintly worn crowns.

\section{MB07H2M16:}

A nearly complete skeleton. The right hand, femur, tibia and fibula (except for the distal ends of the latter), as well as the left foot, are missing. The deciduous teeth are fully erupted, except for the deciduous second molars which are in the process of erupting.

\section{MB07H2M17:}

Skull: The cranium is almost completely preserved, including a full set of permanent teeth exhibiting slight occlusal wear (score: 1), with the exception of the third molars which are partially erupted. Dental preservation:

\begin{tabular}{llllllll|llllllll}
$\mathrm{X}$ & M2 & M1 & P2 & P1 & C & I2 & I1 & I1 & I2 & C & P1 & P2 & M1 & M2 & X \\
\hline $\mathrm{X}$ & M2 & M1 & P2 & P1 & C & I2 & I1 & I1 & I2 & C & P1 & P2 & M1 & M2 & X
\end{tabular}

Postcranial skeleton: Intrusive destruction post-interment has removed the right distal humerus, ulna, radius, most of the hand, ilium and ischium, most of the sacrum, vertebrae below T9/10, and ribs below the $5^{\text {th }}$; otherwise well preserved. 


\section{MB07H2M18:}

Skull: the cranium is in good condition. The glabella region, superciliary arches, nasal root and nasal bones are quite flat, and the orbital shape is round rather than square. A supraorbital foramen was found on the right side alone. Dental preservation:

\begin{tabular}{llllllll|llllllll}
$\mathrm{X}$ & M2 & M1 & P2 & P1 & C & I2 & I1 & I1 & I2 & C & P1 & P2 & M1 & M2 & X \\
\hline $\mathrm{X}$ & M2 & M1 & P2 & P1 & C & I2 & I1 & I1 & I2 & C & P1 & P2 & M1 & M2 & X
\end{tabular}

The incisor occlusal pattern forms an over-bite. The occlusal surfaces are slightly worn (anterior teeth: score 2, molars: score 2).

Postcranial skeleton: All postcranial elements are in good condition. The scapulae, humeri, radii and ulnae are nearly complete, as are the os coxae, femora and tibiae, but the fibulae are incomplete. The vertebrae, sacrum, and ribs are also in good condition.

\section{MB07H2M19:}

Skull: severely damaged with much of the calvarium and face missing. Only a part of the right parietal bone, maxilla and mandible were excavated in situ. The mastoid processes are large (score: 4), as is the mandibular body, which exhibits the 'rocker jaw' variant. The gonial angles are moderately everted, with well developed pterygoid muscle attachment surfaces. The mandibular rami are minimally sloping and the mental eminence is weakly protruding (score: 1). Dental preservation:

\begin{tabular}{cccccccc|cccccccc}
0 & M2 & M1 & P2 & P1 & C & X & I1 & I1 & X & C & P1 & P2 & M1 & $/$ & $/$ \\
\hline 0 & X & M1 & P2 & P1 & C & X & X & X & X & C & P1 & P2 & M1 & M2 & M3
\end{tabular}

The incisor occlusal pattern is not assessable. All occlusal surfaces are heavily worn (anterior teeth: score 6, molars: score 4-6).

Postcranial skeleton: All postcranial remains are in a good state of preservation. The humeri, radii and ulnae are nearly complete, as are the femora, tibiae, fibulae and patellae. The muscle attachment areas represented by the deltoid tuberosity of the humerus and the pilastric form of the femoral linea aspera, were well developed. Most of the vertebrae were preserved.

\section{MB07H2M20:}

A fragmentary and fragile skeleton only missing the hands.

\section{MB07H2M21:}

Reasonable condition, albeit fragmentary. Missing the left half of the cranium, right ribs, humerus, most foot phalanges and the sacrum.

\section{MB07H2M22}

Skull: perfectly preserved. The calvarium is brachycephalic shape (cranial index: 80.1) and the glabella region, superciliary arches and nasal root are quite flat. The nasal bones are slightly elevated. The orbital shape is round rather than squared 


\section{H. MATSUMURA ET AL.}

and a supraorbital foramen is present on the left side only. The zygomatic bones are moderately projecting laterally, the forehead is of moderate width, the supranasal suture is faintly present, and the temporal lines are distinct on the parietal bones. The size of the mastoid processes is small (score: 2). The external occipital protuberance is not ridged (score: 1), the superior and inferior nuchal lines are indistinct and the nuchal plane is quite smooth. The coronal and lambdoidal sutures are minimally fused synostosed and the sagittal suture is partially synostosed ectocranially. Endocranial synostosis could not be assessed. The width/height proportion of facial skeleton is moderate, as indicated by a facial index of 54.3. The mandibular body is gracile, but the chin is relatively high. The pterygoid muscle attachment surfaces are smooth, and the gonial angles are slightly everted. The narrow rami have a slight slope. The mental eminence is weak (score: 2), but the baseline of the body is slightly curved, exhibiting the 'rocker jaw' variant. Dental preservation:

\begin{tabular}{cccccccc|cccccccc}
$\mathrm{X}$ & $\mathrm{M} 2$ & $\mathrm{M} 1$ & $\mathrm{P} 2$ & $\mathrm{P} 1$ & $\mathrm{C}$ & $\mathrm{I} 2$ & $\mathrm{I} 1$ & $\mathrm{I} 1$ & $\mathrm{X}$ & $\mathrm{C}$ & $\mathrm{P} 1$ & $\mathrm{P} 2$ & $\mathrm{M} 1$ & 0 & $\mathrm{X}$ \\
\hline $\mathrm{X}$ & $\mathrm{M} 2$ & $\mathrm{M} 1$ & $\mathrm{P} 2$ & $\mathrm{P} 1$ & $\mathrm{C}$ & $\mathrm{I} 2$ & $\mathrm{I} 1$ & $\mathrm{I} 1$ & $\mathrm{I} 2$ & $\mathrm{C}$ & $\mathrm{P} 1$ & $\mathrm{P} 2$ & $\mathrm{M} 1$ & $\mathrm{M} 2$ & $\mathrm{X}$
\end{tabular}

The incisor occlusal pattern is an over-bite. The tooth crown surfaces are moderately worn (anterior teeth score: 4, molars score: 4-5).

Postcranial skeleton: most elements are nearly complete, but most tarsals, all metatarsals and foot phalanges, most elements of the left hand, and a few distal phalanges from the right hand are missing. The long bones are relatively slender, and the development of muscle attachment sites is minimal. Clear squatting facets are present on the tali.

\section{MB07H2M23:}

See entry in Appendix 1.

\section{MB07H2M24:}

Skull: The facial region was heavily damaged postmortem, but the calvarium and mandible are in relatively good condition. The forehead is broad and relatively vertical. The parietal bones are not smoothly rounded at the sagittal suture. The supranasal suture is absent and the glabella region and superciliary arches are very flat. The superior orbital margin of the frontal bone is weakly rounded and supraorbital foramina are bilaterally absent. The temporal lines are not distinguishable at all on the parietal bones. The mastoid processes are small (score: 2 ), and the external occipital protuberance is flat (score: 1). Both the superior and inferior nuchal lines are definable, although the nuchal plane is quite smooth. The coronal, sagittal and lambdoidal sutures are not synostosed either ecto or endocranially. The mandibular body is relatively thick and robust and the mental eminence is distinctive (score 3). The status of the gonial angles, ramus angle and pterygoid muscle attachment site rugosity are all unobservable due to postmortem damage. Dental preservation: 


\begin{tabular}{cccccccc|cccccccc}
$\mathrm{X}$ & $\mathrm{X}$ & $\mathrm{M} 1$ & $\mathrm{P} 2$ & $\mathrm{P} 1$ & $\mathrm{C}$ & $\mathrm{X}$ & $/$ & $/$ & $/$ & $/$ & $/$ & $/$ & $/$ & $/$ & $/$ \\
\hline $\mathrm{X}$ & $\mathrm{M} 2$ & $\mathrm{M} 1$ & $\mathrm{P} 2$ & $\mathrm{P} 1$ & $\mathrm{C}$ & $\mathrm{X}$ & $\mathrm{X}$ & $\mathrm{X}$ & $\mathrm{X}$ & $\mathrm{C}$ & $\mathrm{P} 1$ & $\mathrm{P} 2$ & $\mathrm{M} 1$ & $\mathrm{M} 2$ & 0
\end{tabular}

The incisor occlusal pattern is not assessable. The tooth crown surfaces were worn (score: 5 for both the anterior and posterior teeth).

Postcranial skeleton: most postcranial elements are in a moderate state of preservation, with some areas damaged. Both upper limbs and the right lower limbs are preserved. The long bones are relatively slender and their robustness, including the development of muscle attachment sites, is moderate. Although preservation of the vertebrae and ribs is poor, the sacrum and the lumbar vertebrae are in relatively good condition.

\section{MB07H2M25:}

See entry in Appendix 1.

\section{MB07H2M26:}

Well preserved, only missing the hands and feet, sacrum, and distal right tibia and fibula. The deciduous teeth are fully erupted, with the exception of the deciduous second molars.

\section{MB07H2M27:}

Skull: nearly intact. The cranial index is 70.3 (Martin No. 8:1), indicating a dolichocephalic cranium. The upper facial index is 55.6 (Martin No. 48:45), categorizing the facial region as high and narrow. The forehead is narrow, with a prominent frontal tubercle. The parietal bones are moderately angled at the sagittal suture and the frontal bone slopes steeply. The supranasal suture is present, while the glabella region, superciliary arches and nasal root are relatively flat. The orbital shape is slightly round, and supraorbital foramina exist bilaterally. The zygomatic bones strongly project laterally, while the temporal lines are distinct on the parietal bones. The size of the mastoid process is moderate (score: 3 ) and the external occipital protuberance is moderately protruding (score: 3 ). The superior and inferior nuchal lines are distinct upon a rugged nuchal plane. The coronal, sagittal and lambdoidal sutures are not synostosed ectocranially and are not assessable endocranially. The mandibular body is tall, thick and robust, with a perpendicular gonial region. The pterygoid muscle attachment surfaces are smooth, and the rami are moderately sloping. The mental eminence is distinctively protruding (score: 3), but the baseline of the mandibular body does not exhibit the 'rocker jaw' variant. Dental preservation:

\begin{tabular}{llllllll|llllllll} 
M3 & M2 & M1 & P2 & P1 & C & X & X & I1 & X & C & P1 & P2 & M1 & M2 & M3 \\
\hline M3 & M2 & M1 & P2 & P1 & C & X & X & X & X & C & P1 & P2 & M1 & M2 & M3
\end{tabular}

The incisor occlusion pattern was originally an edge-to-edge bite. The occlusal surfaces are severely worn (anterior and posterior teeth: score 5).

Postcranial skeleton: all postcranial elements are in good condition. The scapulae, humeri, radii and ulnae are nearly complete, as are the os coxae, femora, tibiae, fibulae and patellae. The deltoid muscle attachment areas of the humeri are robust, 


\section{H. MATSUMURA ET AL.}

as are the leg muscles, presumed from the pilastric form of the linea aspera of the femora and the highly curved femoral shafts. The vertebrae, sacrum and ribs remain in good condition as well. Squatting facets are present on both tali.

\section{MB07H2M28:}

Reasonable preservation, although both hands and feet, most epiphyses, left fibula, distal right fibula, and distal right radius and ulna are missing. No dentition observable or recovered.

\section{MB07H2M29:}

The preservation is reasonable but the entire cranium is missing, and the mandible is broken in two, with both halves facing outwards. The entire right hand, most of the left hand, and most of both feet (except for the left talus, cuboid and medial cuneiform and right talus and cuboid) are missing. The deciduous molars show heavy attrition, but only the permanent incisors and first molars have erupted.

\section{MB07H2M30:}

Skull: good condition, although the neuro-cranium was obliquely deformed to a certain extent, probably due to subterranean soil pressure. Overall, this skull is large in size and robust in morphology. The upper facial index is 44.9 (Martin No. 48:45), describing the facial height to breadth ratio as low and broad. The forehead is wide and the frontal tubercle is very clear, while the parietal bones are not well angled at the sagittal suture and the frontal itself is minimally sloped. The supranasal suture is present but faint, and the glabella region and superciliary arches are moderately protruding (supra orbital ridge, score: 3). Orbital shape is square rather than round and supraorbital foramina are present bilaterally. The lateral projection of the zygomatic bones is strong, forming a very broad facial profile and the temporal lines are distinct on the parietal bones. The size of the mastoid processes are also very large (score: 5), while the external occipital protuberance is minimally protruding (score: 2). Both the superior and inferior nuchal lines are distinctive, with a very rugged nuchal plane. The coronal, sagittal and lambdoidal sutures are slightly synostosed ectocranially, while endocranial sagittal and lambdoidal suture synostosis is considerable. The mandibular body is tall, thick and robust. Although the gonial angles are minimally everted, the pterygoid muscle attachment surfaces are well developed. The mandibular rami are wide and slightly sloping. The mental eminence is moderately protruding (score: 3 ). The baseline of the mandibular body exhibits a faint 'rocker jaw' shape. Dental preservation:

\begin{tabular}{cccccccc|cccccccc}
$\mathrm{X}$ & $\mathrm{X}$ & $\mathrm{X}$ & 0 & $\mathrm{P} 1$ & $\mathrm{C}$ & $\mathrm{X}$ & $\mathrm{I} 1$ & $\mathrm{I} 1$ & $\mathrm{X}$ & $\mathrm{C}$ & $\mathrm{P} 1$ & $\mathrm{P} 2$ & $\mathrm{M} 1$ & $\mathrm{X}$ & $\mathrm{X}$ \\
\hline $\mathrm{M} 3$ & $\mathrm{M} 2$ & $\mathrm{M} 1$ & $\mathrm{P} 2$ & $\mathrm{P} 1$ & $\mathrm{C}$ & $\mathrm{I} 2$ & $\mathrm{I} 1$ & $\mathrm{I} 1$ & $\mathrm{I} 2$ & $\mathrm{C}$ & $\mathrm{P} 1$ & $\mathrm{P} 2$ & 0 & $\mathrm{M} 2$ & M3
\end{tabular}

Incisor occlusion was an edge-to-edge bite. Occlusal wear was heavy attrition (anterior teeth, score: 5-6, molar's score: 5-7).

Postcranial skeleton: good condition. The scapulae, humeri, radii and ulnae are nearly complete, as are the os coxae, femora, tibiae, fibulae and patellae. The 
deltoid muscle attachment areas of the humeri are quite robust and the leg muscles are also well developed, indicated by the pilastric form of the femoral linea aspera and the highly curved shafts. The vertebrae, sacrum and ribs are also in good condition. Squatting facets are present on the tali.

\section{MB07H2M31:}

A well preserved skeleton only missing most of the right hand, the left carpals and distal phalanges, distal phalanges from both feet and most of the sacrum. All deciduous teeth are fully erupted.

\section{MB07H2M32:}

Skull: excellent preservation. The cranial index is 74.4 (Martin No. 8:1), indicating a dolichocephalic shape. The upper facial index is 50.7 (Martin No. 48:45), classifying the facial height to breadth ratio as medium. The forehead of the frontal bone is broad and the frontal tubercle is sharp. The frontal bone is steeply sloping and the parietal bones are moderately angled at the sagittal suture. The supranasal suture is present but faint, while the glabella region and superciliary arches are moderately protruding (supra orbital ridge, score: 3) and the nasal root is very concave. The orbital shape is square rather than round and supraorbital foramina are present bilaterally. The lateral projections of the zygomatic bones are pronounced, forming a very broad facial profile. The wide piriformis of the nasal opening is another peculiarity of this specimen. The temporal lines are visible on the parietal bones, the size of the mastoid processes are quite large (score: 5), while the external occipital protuberance is minimally protruding (score: 2). Both the superior and inferior nuchal lines are distinguishable within a very rugged nuchal plane. The coronal, sagittal and lambdoidal sutures are not synostosed wither ecto or endocranially. The size and robustness of the mandibular body is moderate when compared to the general Man Bac male subsample. The gonial angles are minimally everted, but the pterygoid muscle attachment surfaces are well developed. Ramus width and angle are also moderate, but the baseline of the mandibular body exhibits a typical 'rocker jaw'. The mental eminence is moderately protruding (score: 3). Dental preservation:

\begin{tabular}{llllllll|llllllll} 
M3 & M2 & M1 & P2 & P1 & C & X & I1 & I1 & X & C & P1 & P2 & M1 & M2 & M3 \\
\hline M3 & M2 & M1 & P2 & P1 & C & X & X & X & X & C & P1 & P2 & M1 & M2 & M3
\end{tabular}

Incisor occlusion cannot be assessed. Tooth wear is minimal (anterior and posterior teeth, score: $3-4)$.

Postcranial skeleton: all postcranial remains are in good condition. The scapulae, humeri, radii and ulnae are almost complete, as are the os coxae, femora, tibiae, fibulae and patellae. The deltoid muscle attachment areas of the humeri are robust, while the lower limb bones suggest that some of the leg muscles were well developed as well. The linea aspera of the femora are pilastric in form and the femoral shafts have pronounced curvatures. The vertebrae, sacrum and ribs are also in good condition. Squatting facets are present on the tali. 


\section{LITERATURE CITED}

Acsádi G, Nemeskéri J. 1970. History of Human Life Span and Mortality. Budapest: Akadémiai Kiadó.

Oxenham MF, Tilley L, Matsumura H, Cuong NL. Thuy NK, Dung NK, Domett K, Huffer D. 2009. Paralysis and severe disability requiring intensive care in Neolithic Asia. Anthropological Science 2: 107-112.

Scott EC. 1979. Dental wear scoring technique. Am J Phys Anthropol 51:213-218.

Smith BH. 1984. Patterns of molar wear in hunter gatherers and agriculturalists. Am J Phys Anthropol 63: 39-56. 


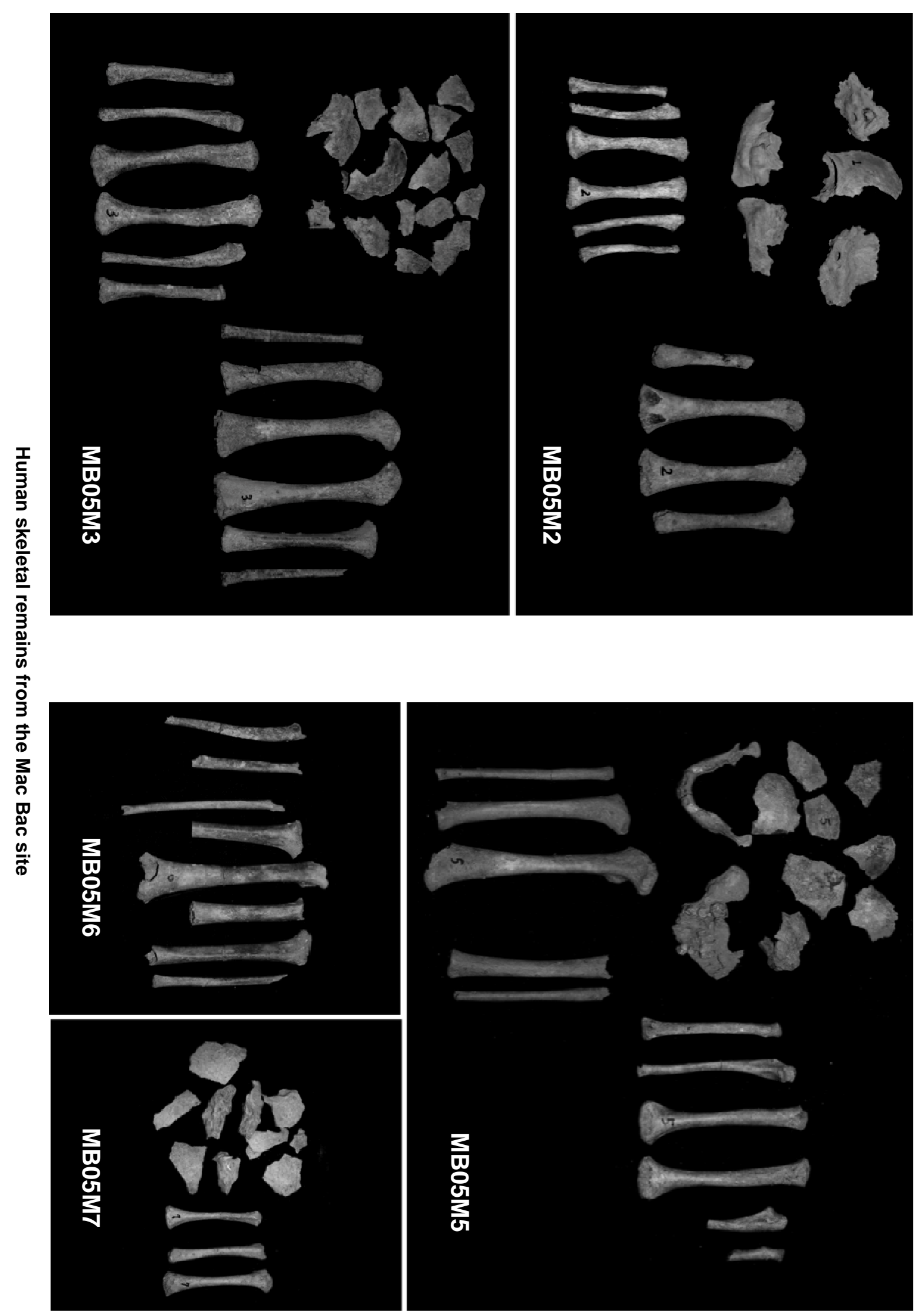




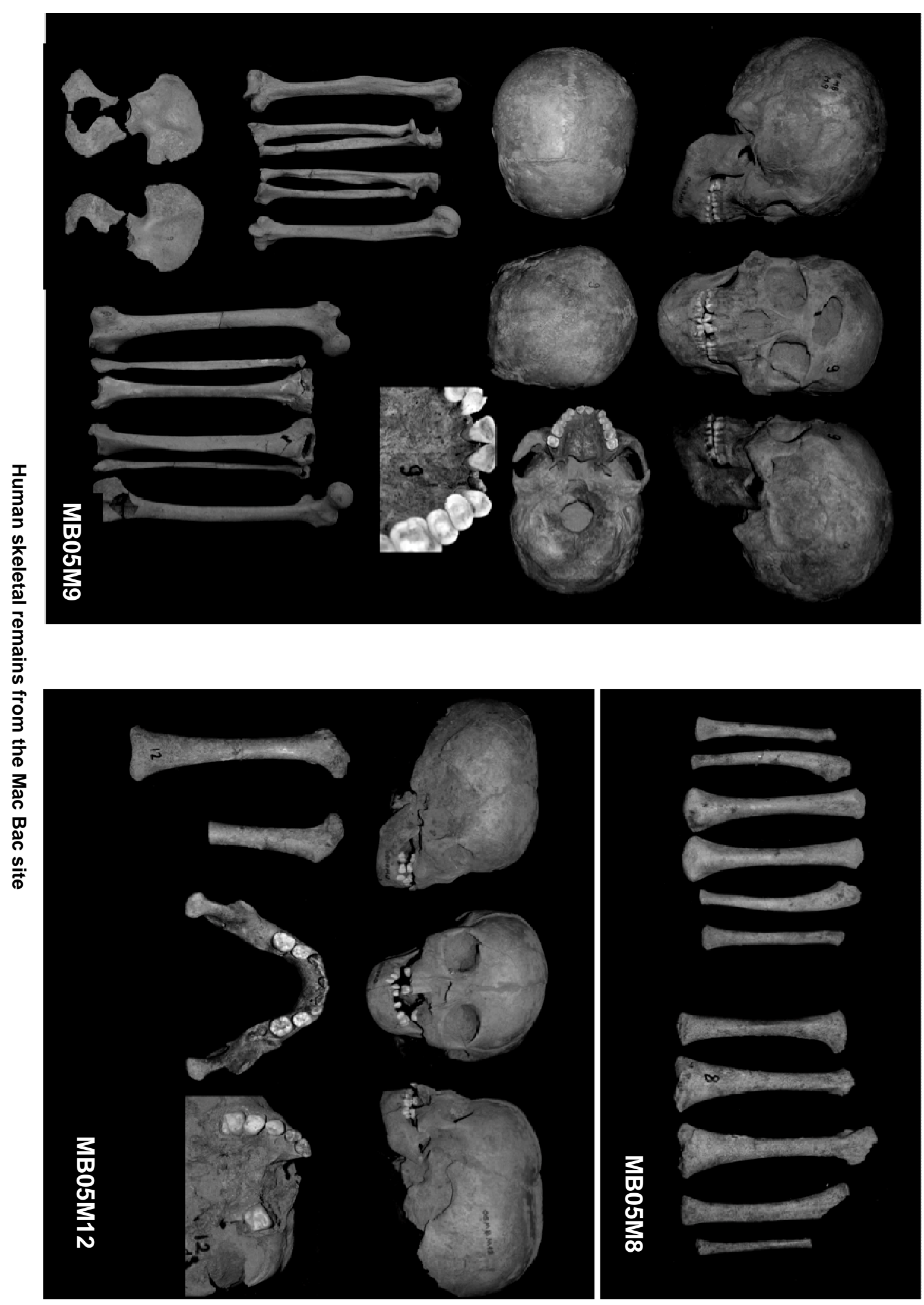




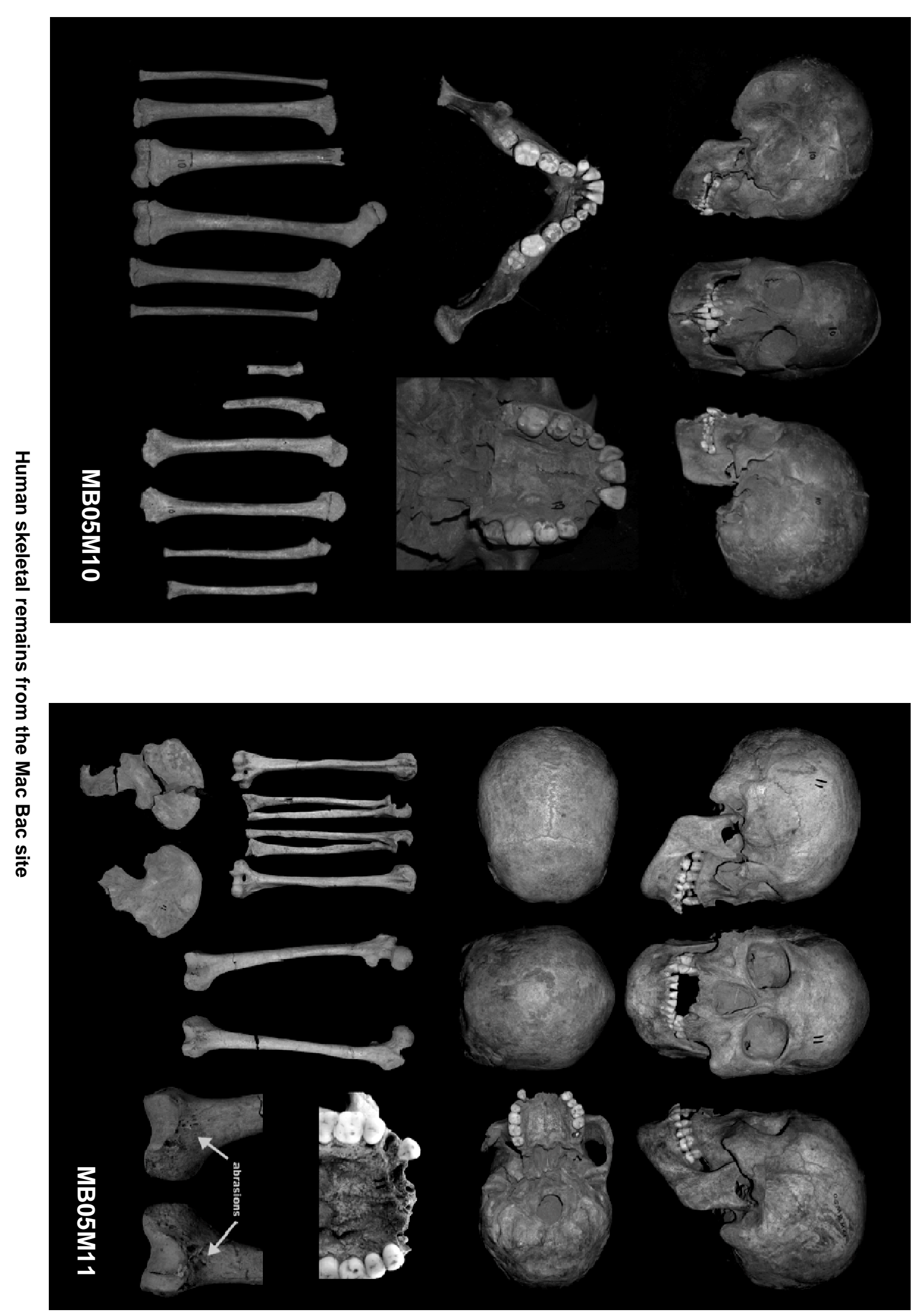




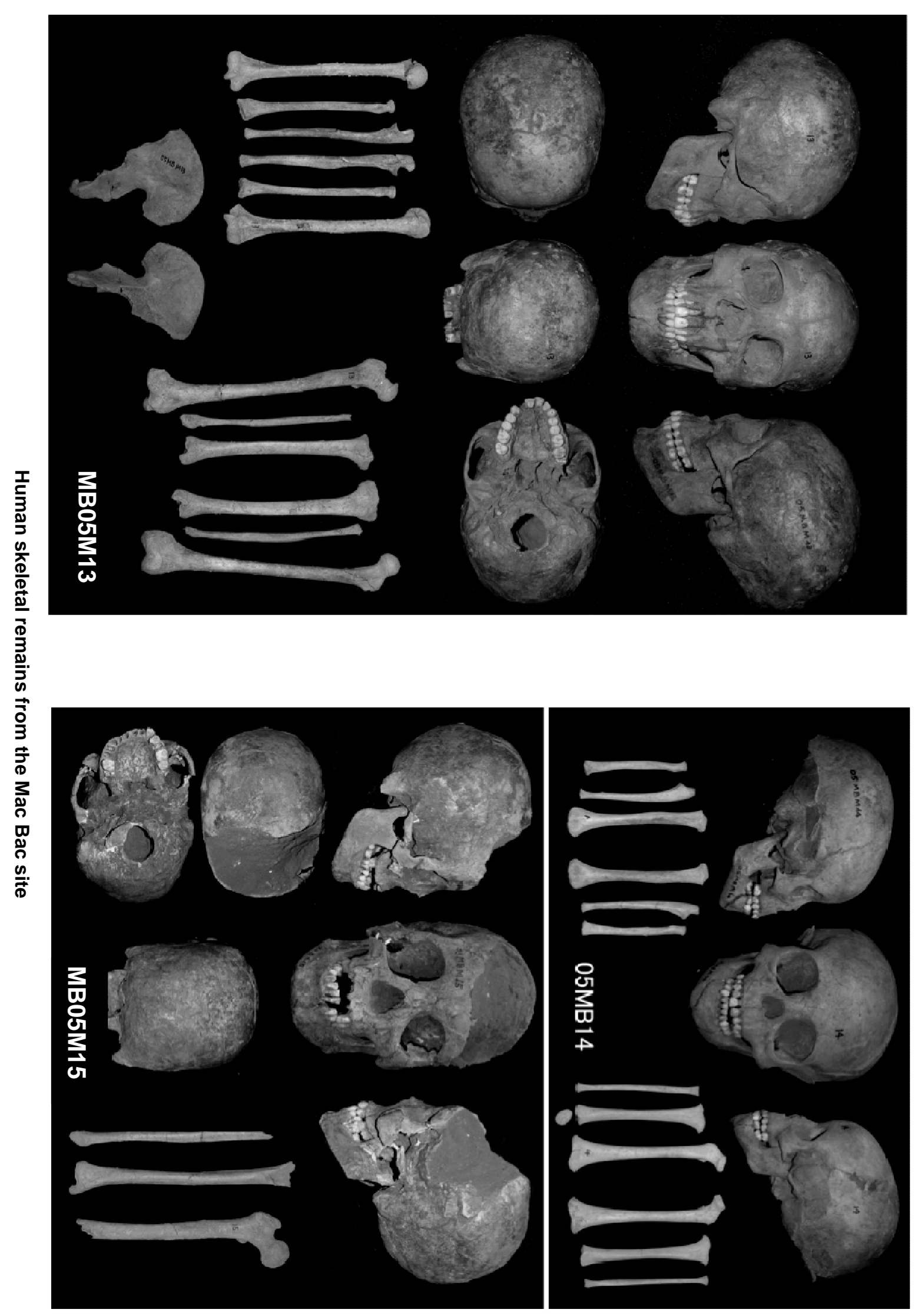




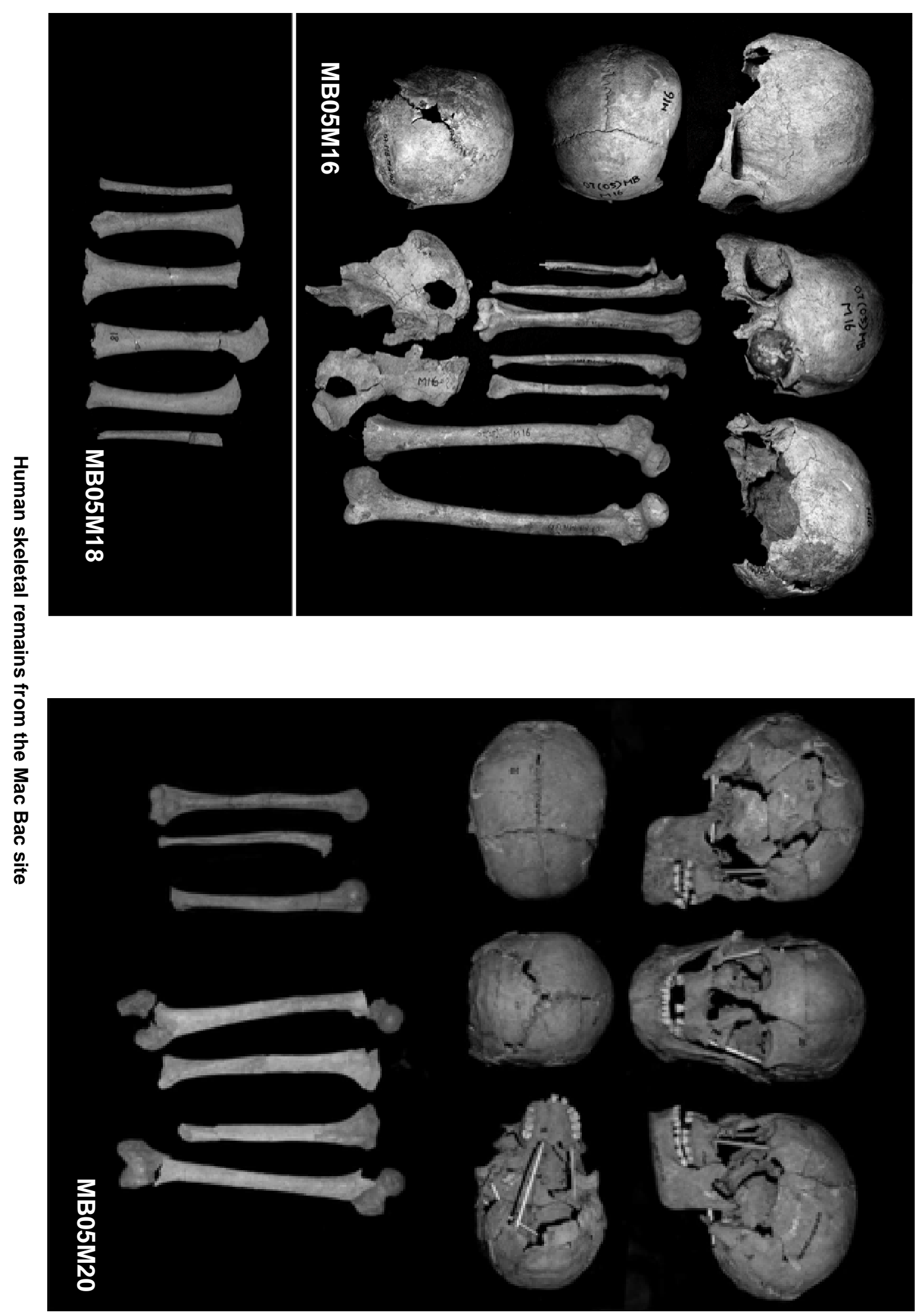




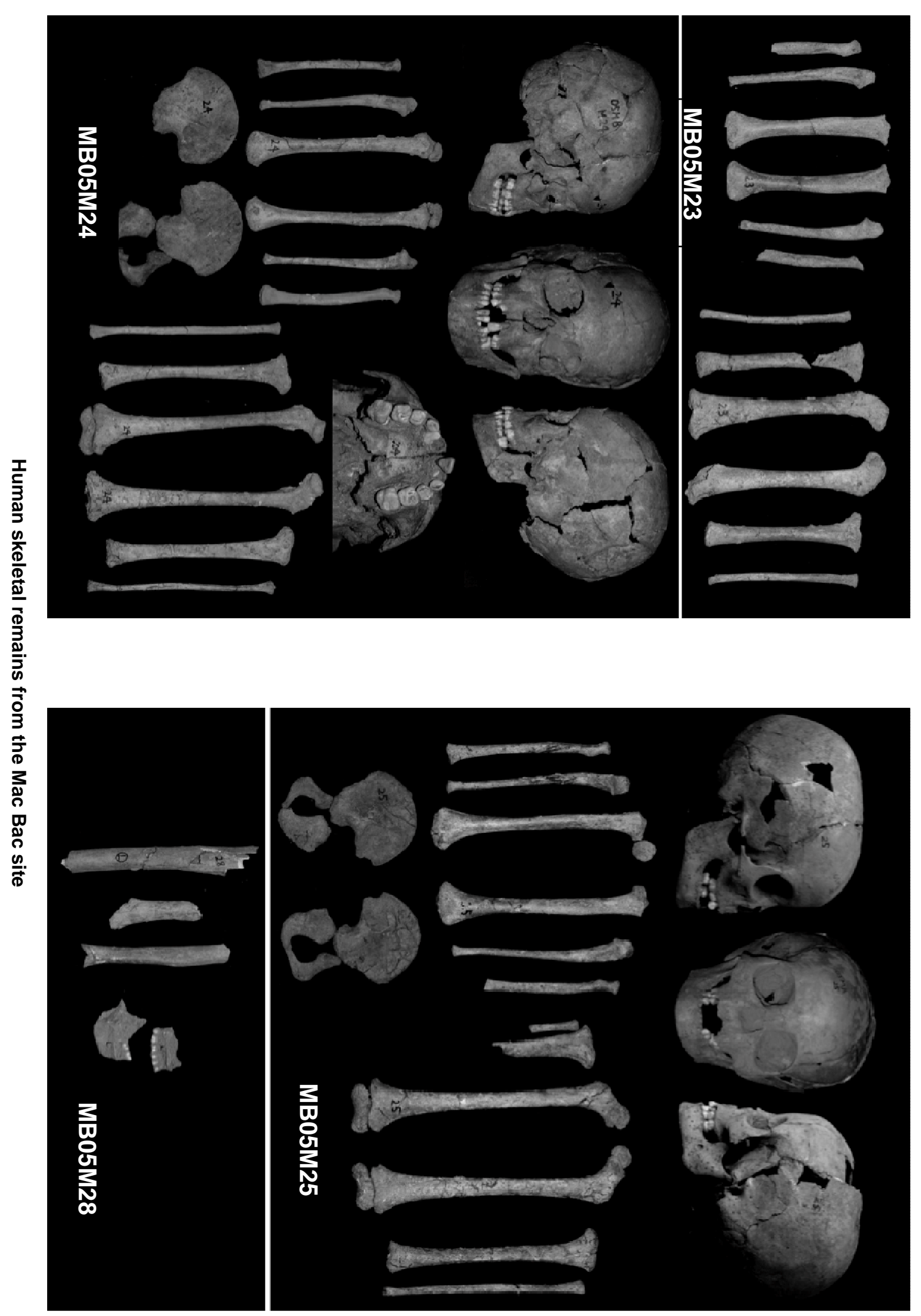




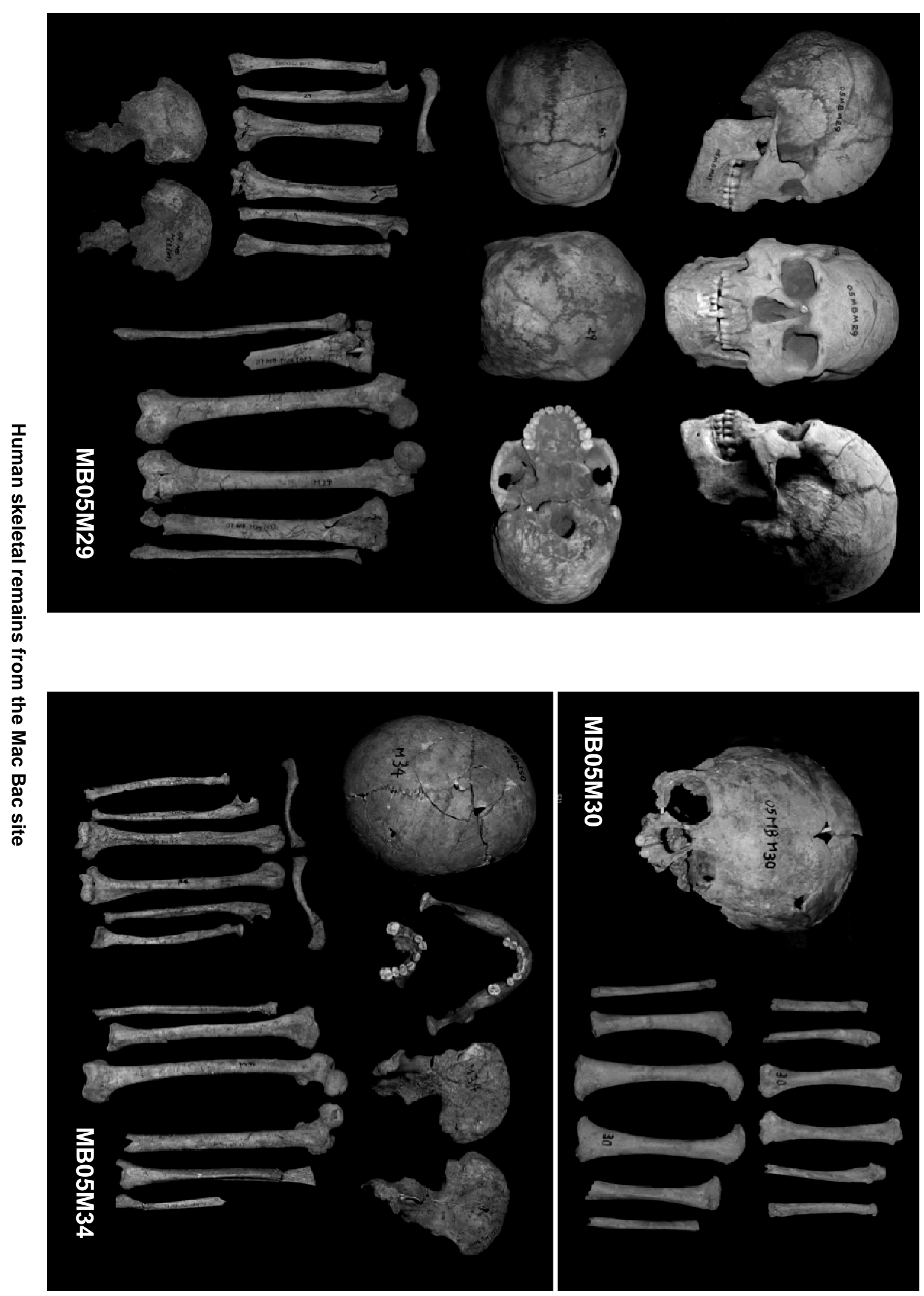




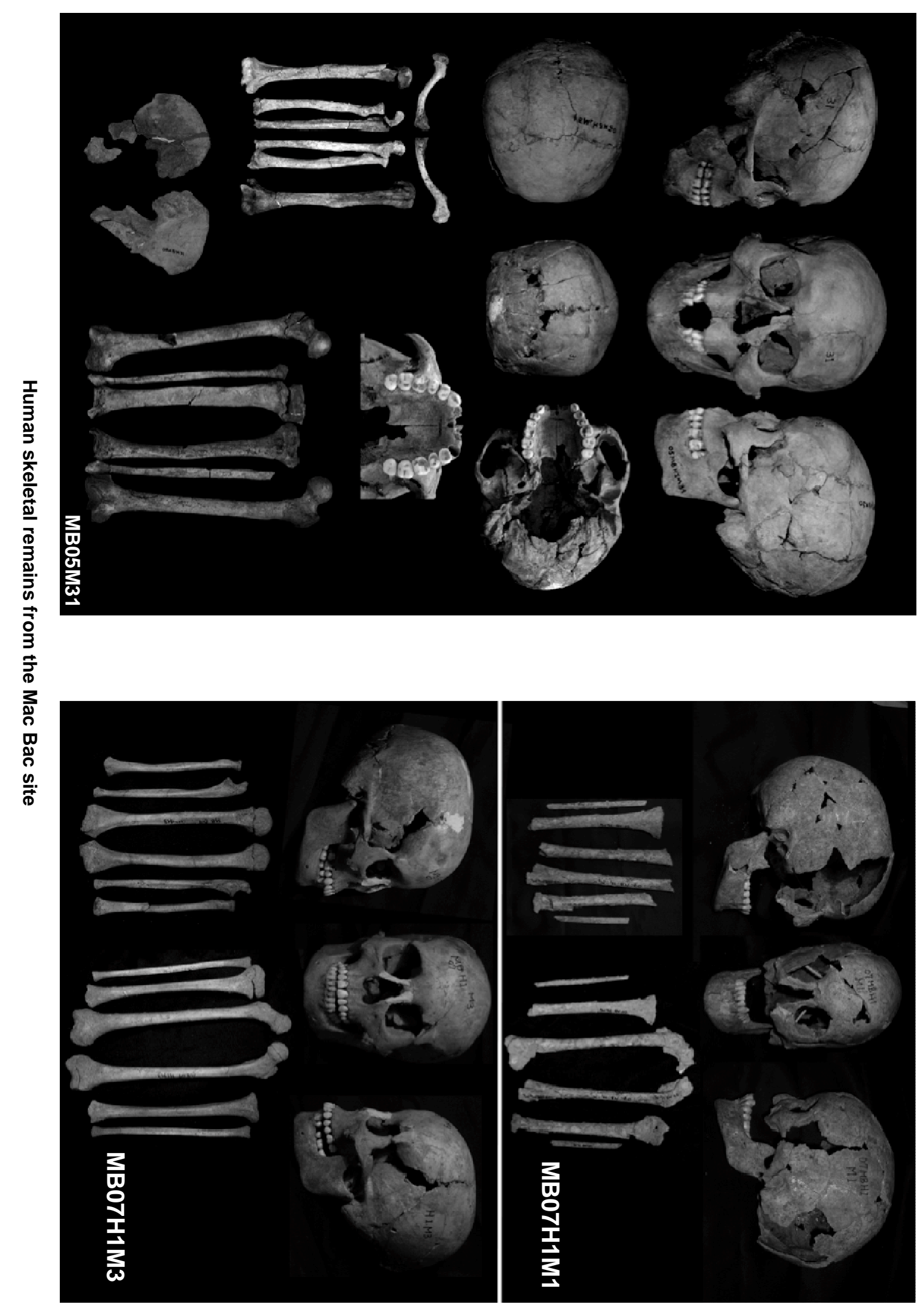




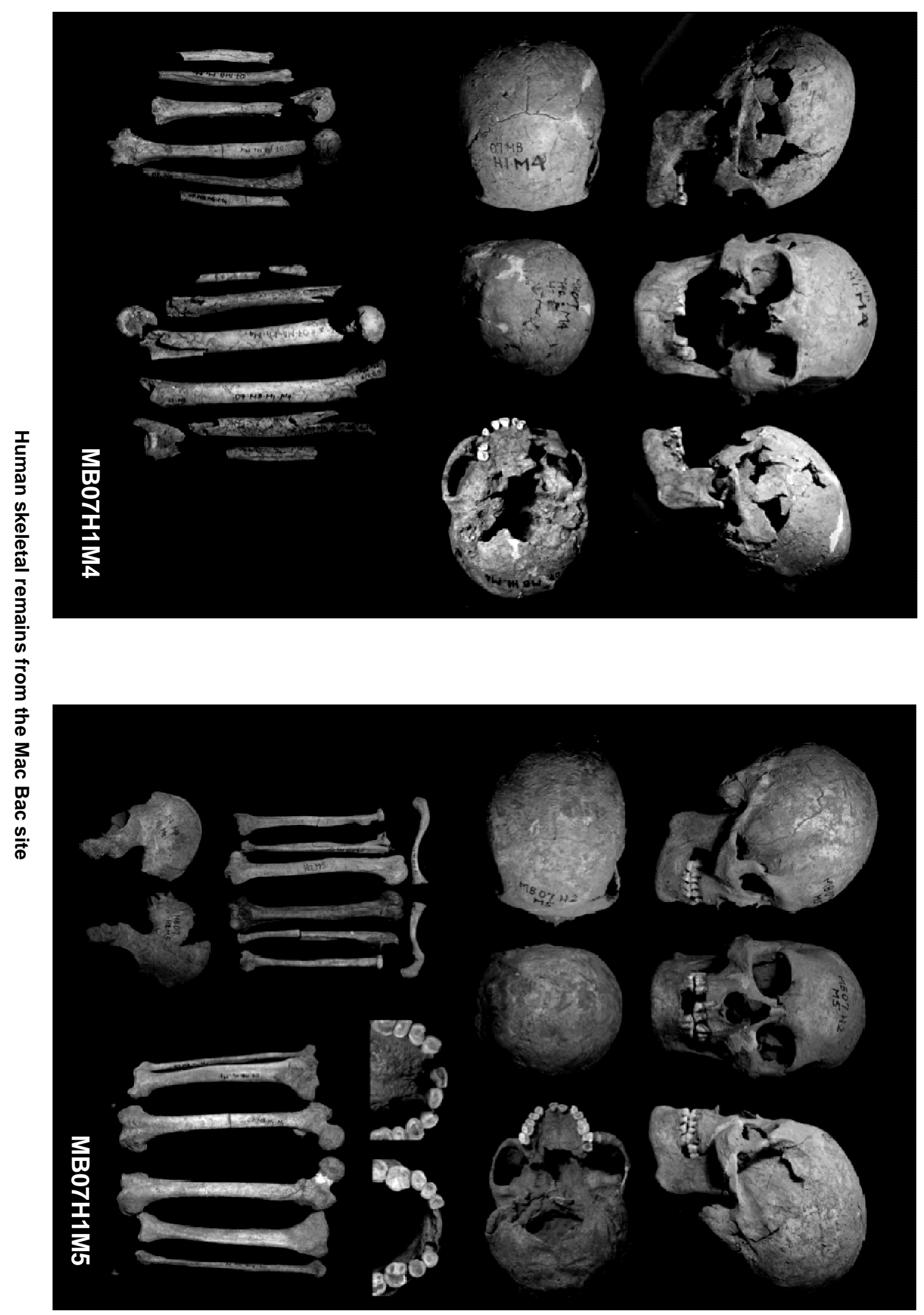




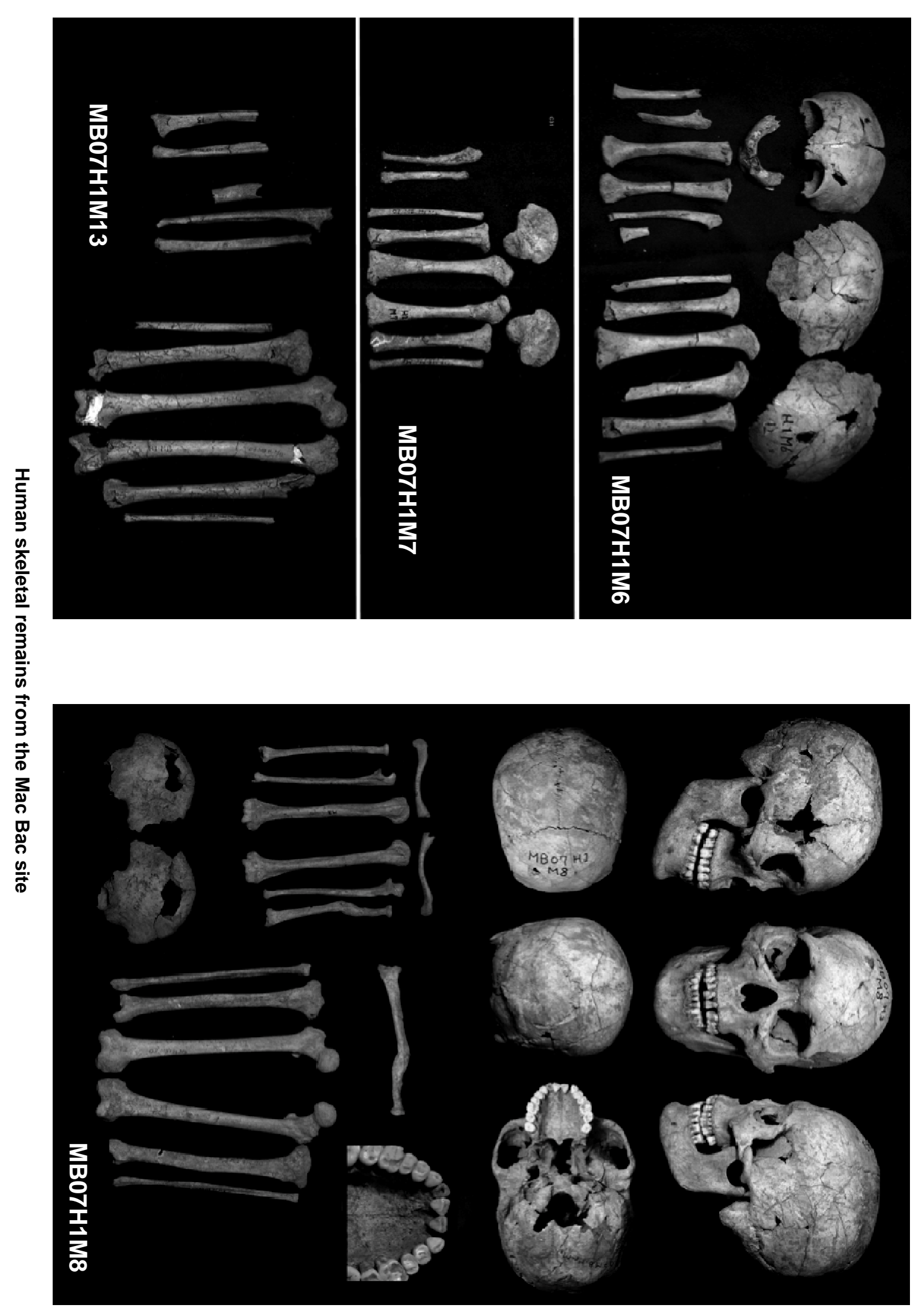




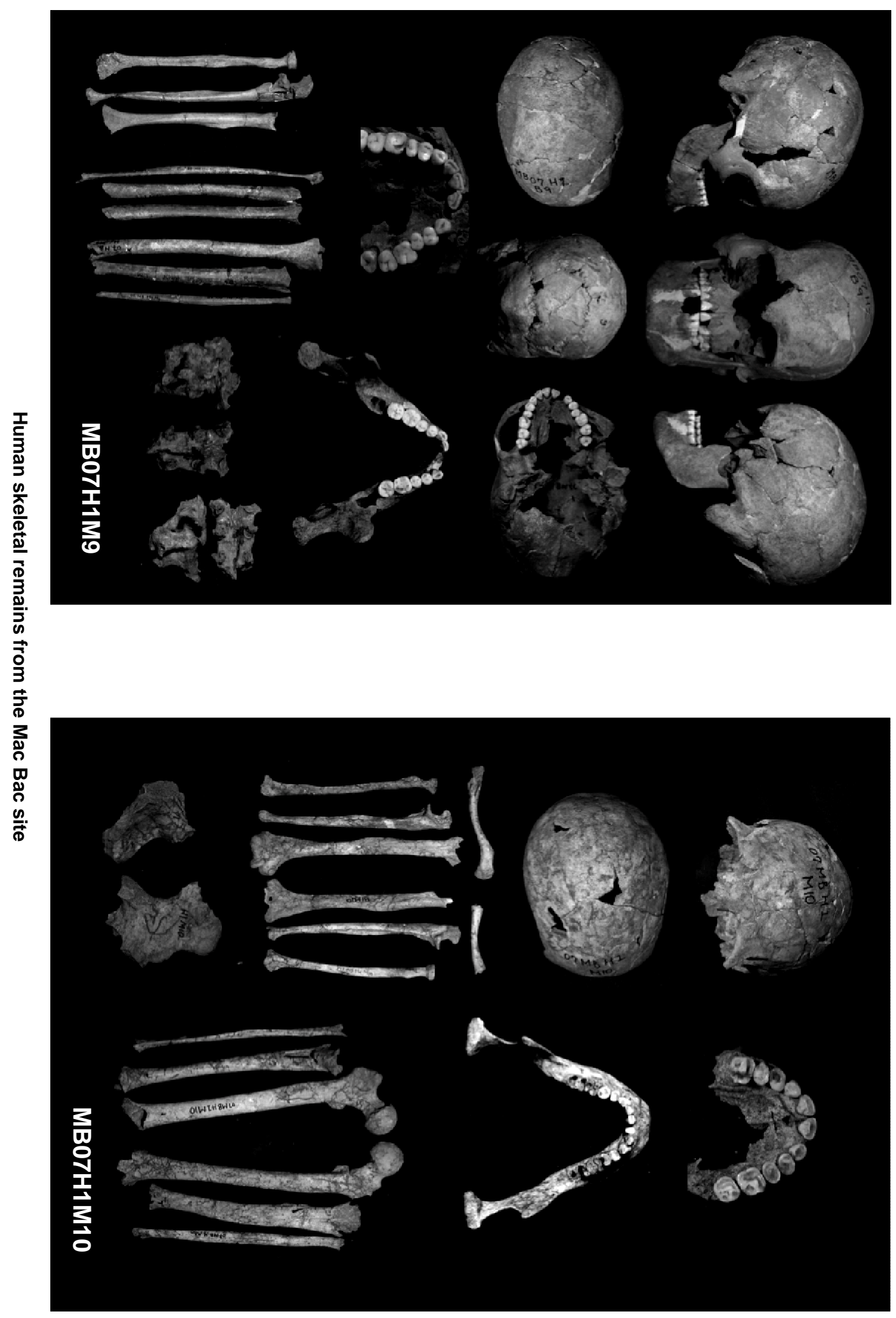




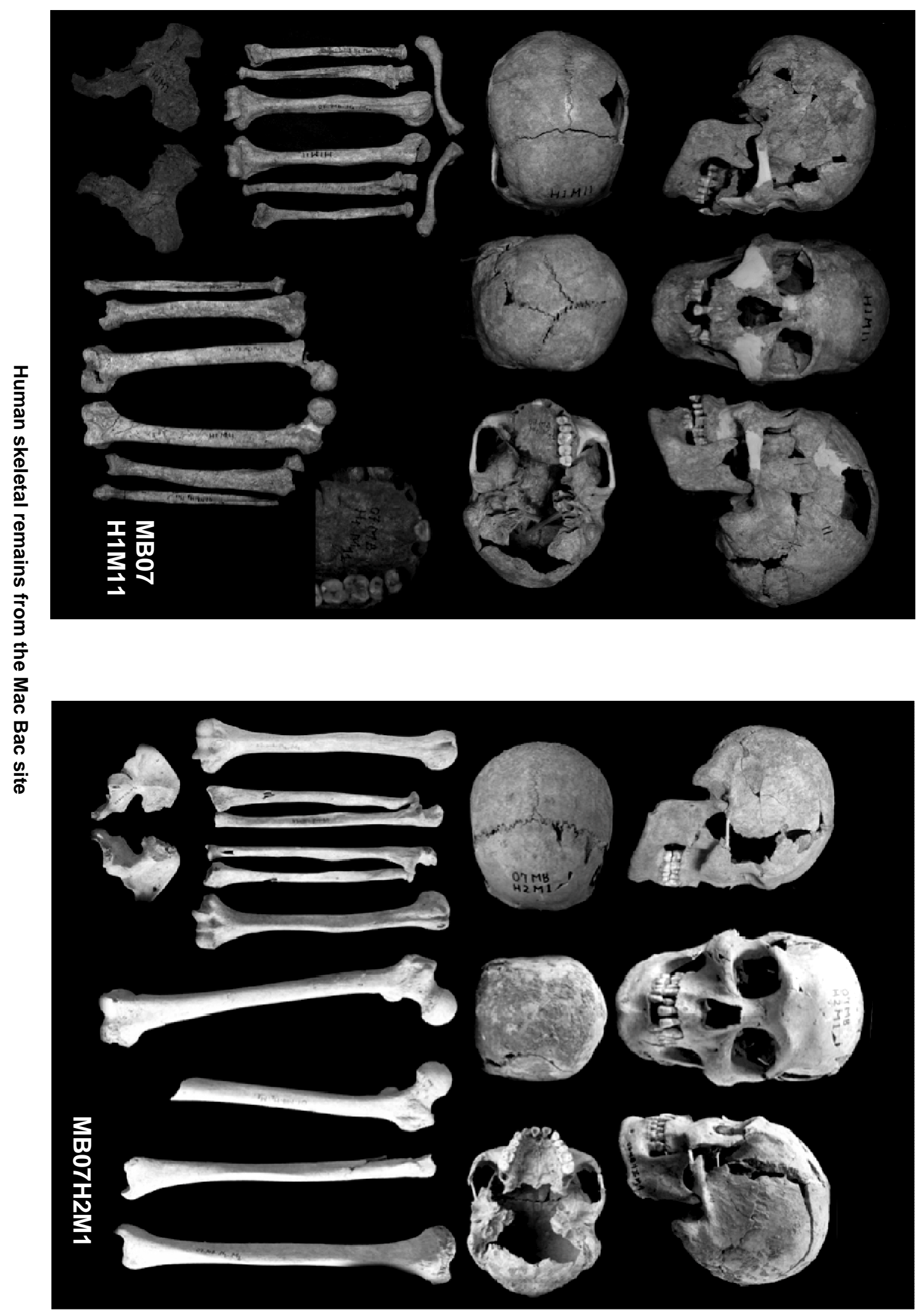




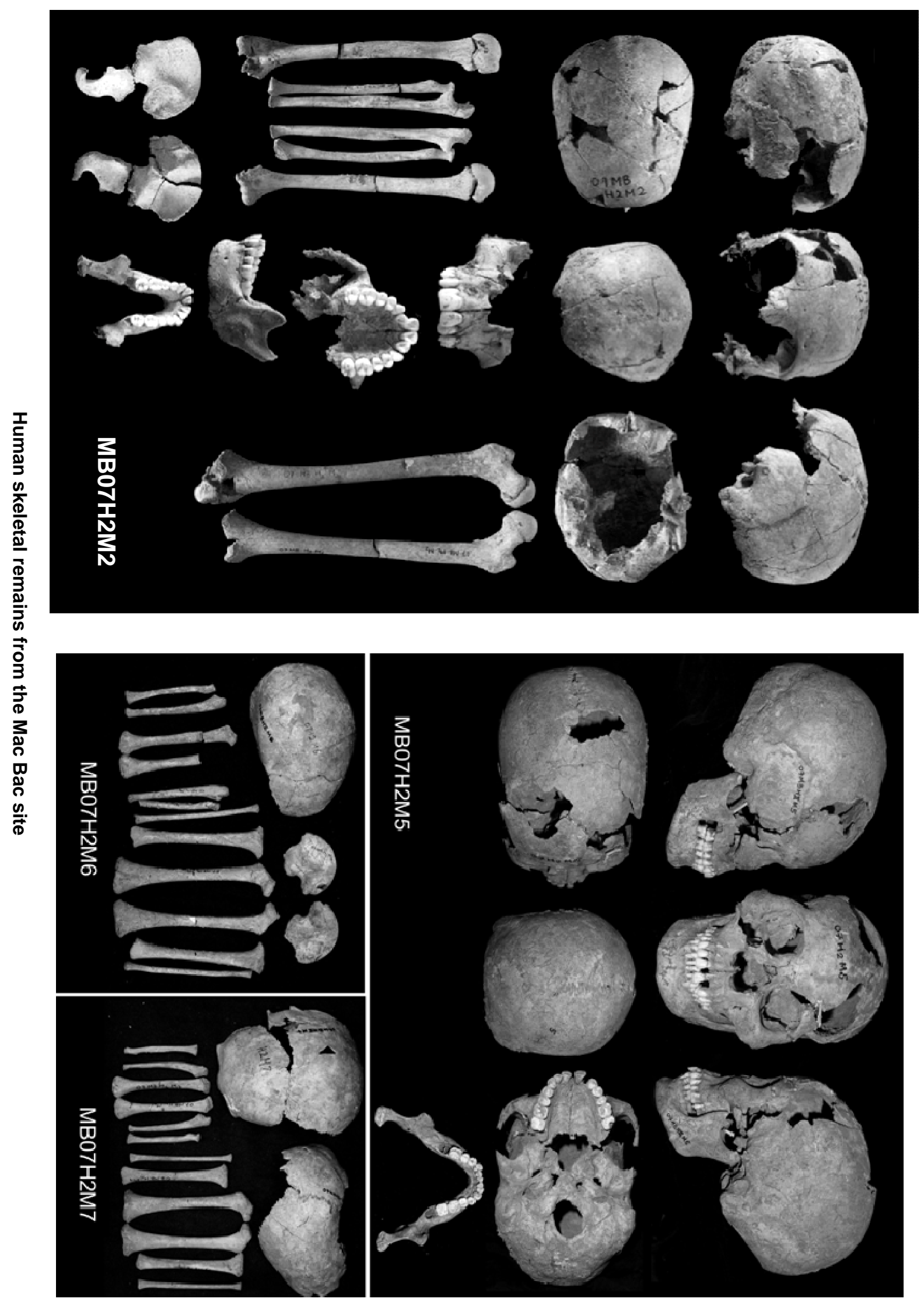




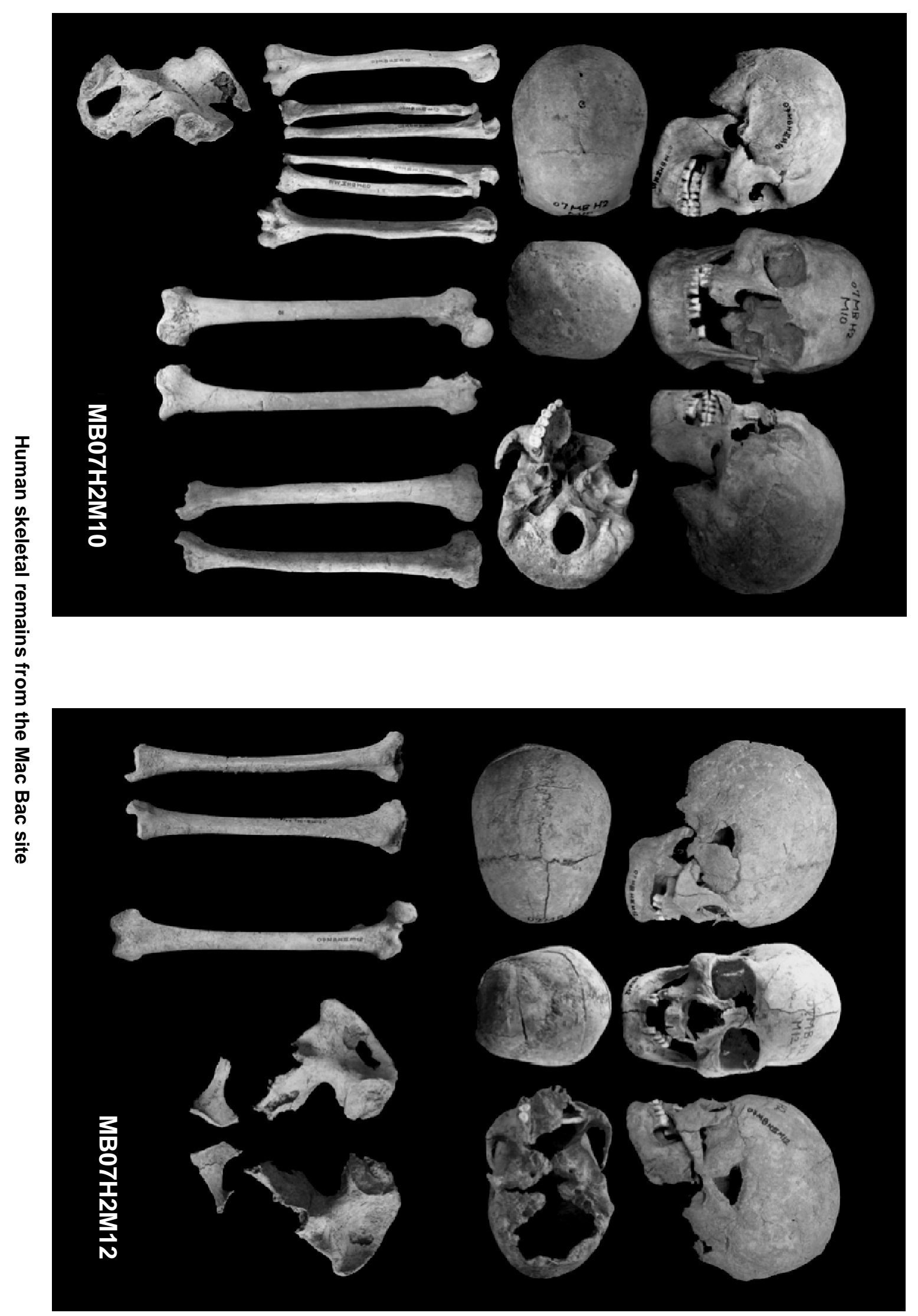




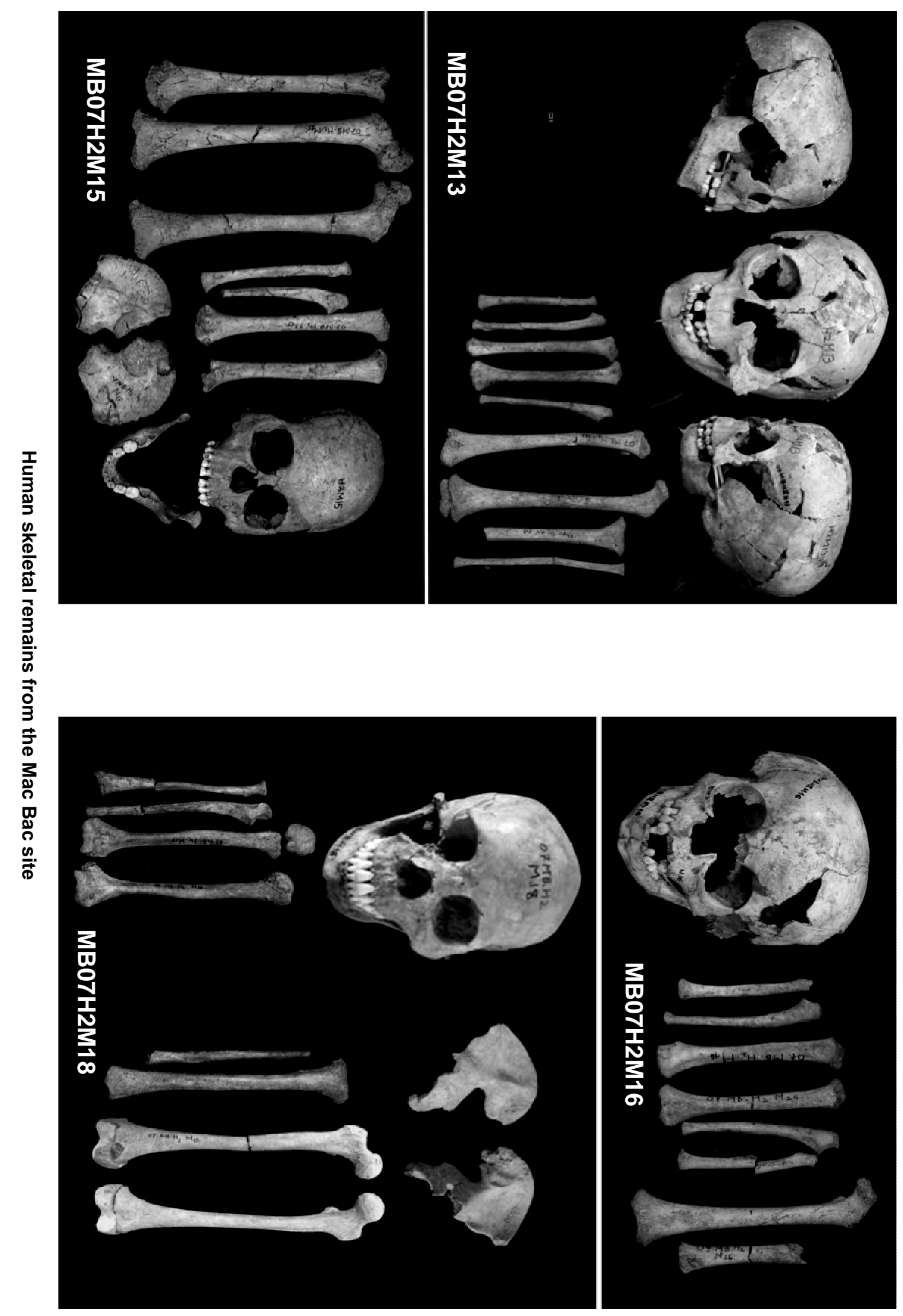




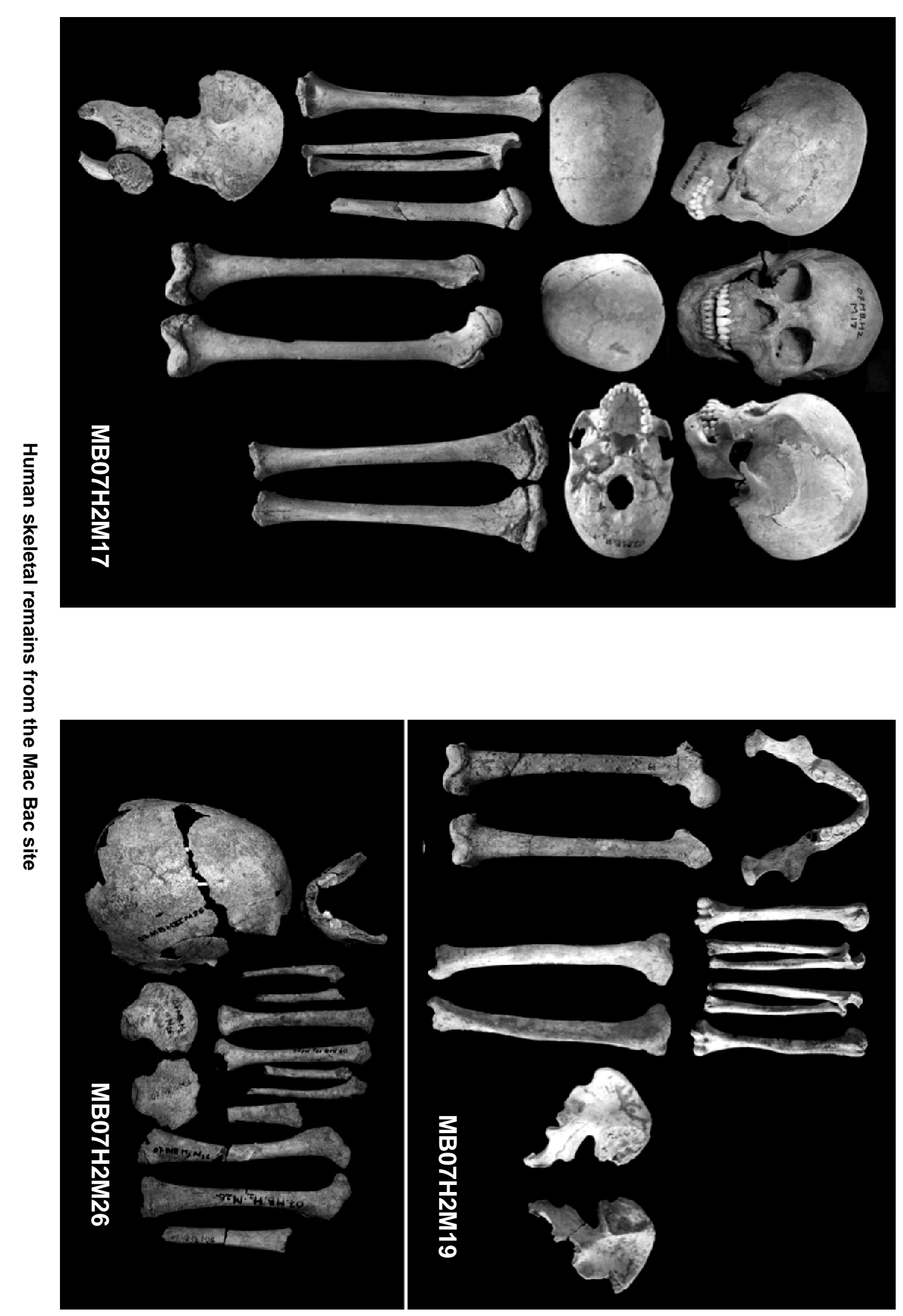




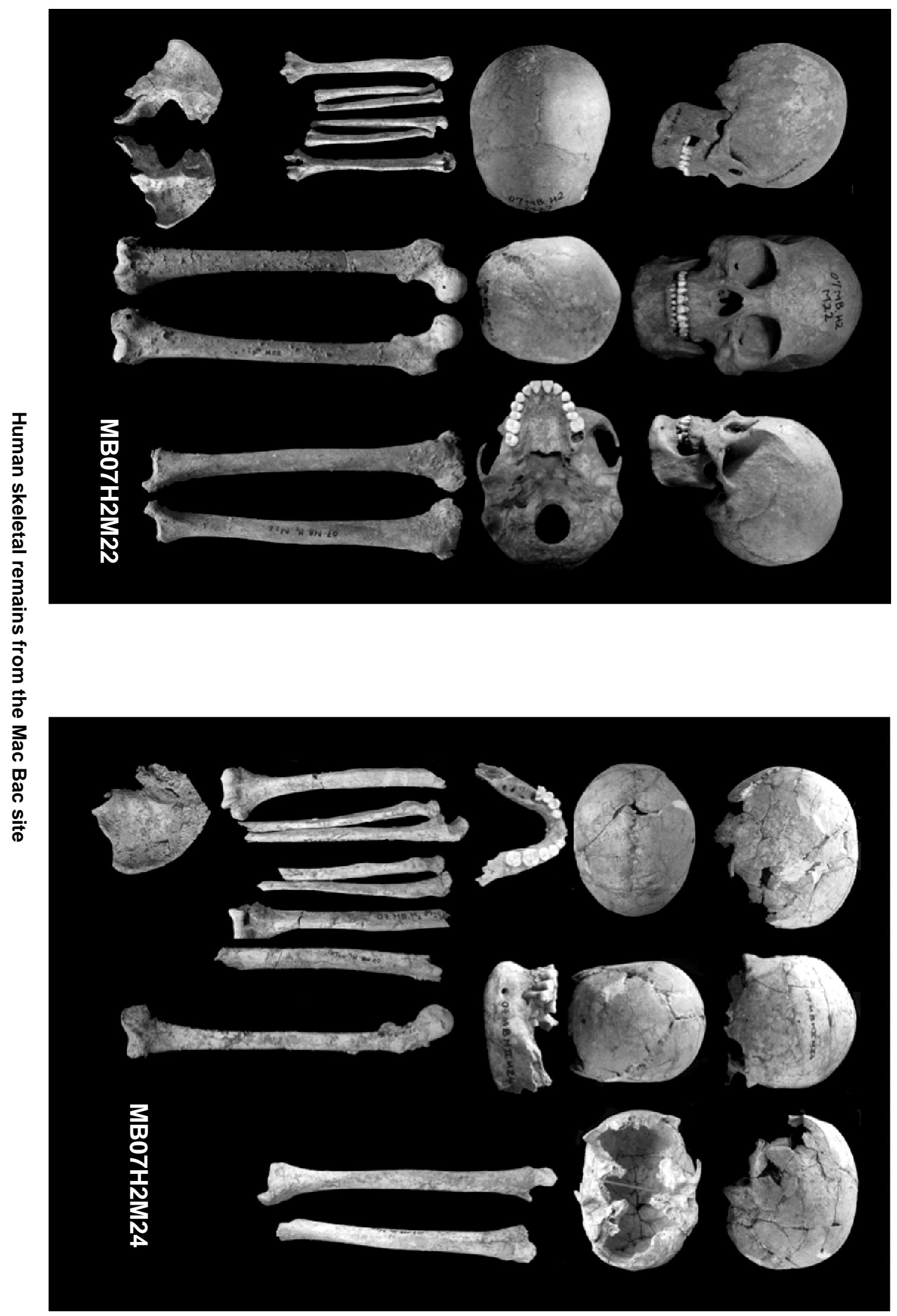




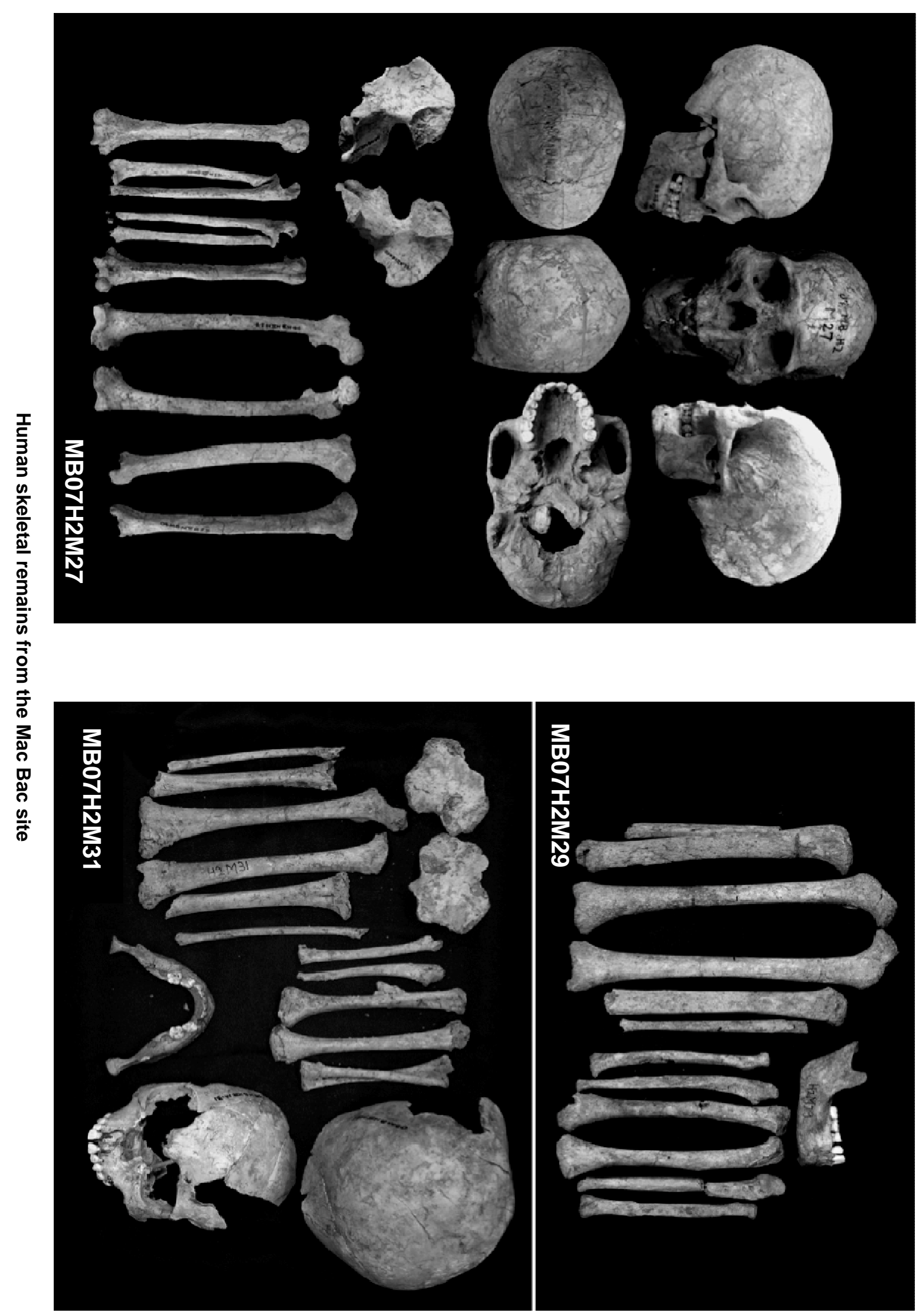

